\title{
WestVirginiaUniversity
}

THE RESEARCH REPOSITORY @ WVU

Graduate Theses, Dissertations, and Problem Reports

2010

\section{The role of nonmuscle Myosin IIA in endothelial cell}

Jing Zhu

West Virginia University

Follow this and additional works at: https://researchrepository.wvu.edu/etd

\section{Recommended Citation}

Zhu, Jing, "The role of nonmuscle Myosin IIA in endothelial cell" (2010). Graduate Theses, Dissertations, and Problem Reports. 4679.

https://researchrepository.wvu.edu/etd/4679

This Thesis is protected by copyright and/or related rights. It has been brought to you by the The Research Repository @ WVU with permission from the rights-holder(s). You are free to use this Thesis in any way that is permitted by the copyright and related rights legislation that applies to your use. For other uses you must obtain permission from the rights-holder(s) directly, unless additional rights are indicated by a Creative Commons license in the record and/ or on the work itself. This Thesis has been accepted for inclusion in WVU Graduate Theses, Dissertations, and Problem Reports collection by an authorized administrator of The Research Repository @ WVU. For more information, please contact researchrepository@mail.wvu.edu. 


\title{
The Role of Nonmuscle Myosin IIA in Endothelial Cell
}

\author{
Jing Zhu \\ A thesis summitted to the \\ School of Medicine \\ at West Virginia University \\ in partial fulfillment of the requirements \\ for the degree of \\ Master of Science \\ in \\ Biomedical Science
}

Department of Physiology \& Pharmacology

Robert Wysolmerski, Ph. D., Chair

Fred Minnear, Ph. D.

Michael D. Schaller, Ph. D.

Department of Physiology \& Pharmacology

Morgantown, West Virginia

2010

Key word: myosin IIA; knock down; endothelial cell; tension; motility 


\begin{abstract}
The Role of Nonmuscle Myosin IIA in Endothelial Cell
\end{abstract}

Jing Zhu

Myosins are molecular motors that convert chemical energy into mechanical force. Vertebrate cells contain three myosin II isoforms, designated as myosin IIA, IIB and IIC, and each isoform has unique biochemical and biophysical charasterics. It is generally accepted that all three isoforms are involved in regulating actin structures and cell contraction. However, it is unknown what role(s) each isoform plays in maintaining actin structures and generating cellular force. Experiments presented in this thesis will begin to document what role myosin IIA plays in endothelial cell contraction and actin dynamics.

Myosin IIA ablated from endothelial cells by infection with adenovirus encoding a short hairpin interfering RNA targeting mouse nonmuscle myosin IIA ( shRNAi-IIA) mediated knockdown of myosin IIA, altered endothelial cell shape and induced reorganization of actin filaments. Myosin IIB content was unaltered and myosin IIB remained associated with actin filaments. Cell attachement and spreading occured faster and there was an increase in cell motility compared to control cultures. Loss of myosin IIA resulted in a $40 \%$ reduction in basal force production and a significantly blunted thrombin induced cell contraction. These results show myosin IIA is needed for normal endothelial cell functions and is essential for generation of basal and agonist-induced force. 


\section{Acknowledgements}

I would like to thank my advisor, Dr. Robert Wysolmerski for his mentorship. This work would not have been possible without his unfaltering support and encouragement. I would also like to thank my committee members, Dr. Fred Minnear and Dr. Michael D. Schaller, for all of their patient guidance, support, and critical reading of my work. I would also like to thank Dr. Zoe Goeckeler and Dr. Karen Martin for their expertise and advice. Finally, I would like to thank Wei Fu and Kimberly Meide for their help and friendship in this wonderful journey. 


\section{Contents}

List of Figures vi

List of Tables vii

Glossary

1 Introduction 1

2 Materials And Methods 4

2.1 Cell Culture and Reagents . . . . . . . . . . . . . . . 4

2.2 Immunofluorescence Microscopy . . . . . . . . . . . . . . . . . . 4

2.3 Virus Amplification . . . . . . . . . . . . . . . . . 5

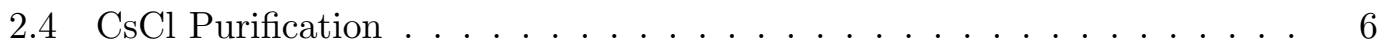

2.5 Adenovirus Infection $\ldots \ldots \ldots \ldots$

2.6 Western Blot Analysis . . . . . . . . . . . . . . 7

2.7 Isometric Tension Measurements . . . . . . . . . . . . . . . 7

2.8 Attachment and Spreading Measured by ECIS . . . . . . . . 8

2.9 Cell Motility . . . . . . . . . . . . . . . . . 8

3 Results 10

3.1 Adenovirus Infection . . . . . . . . . . . . . . . . . 10

3.2 Myosin II and Actin Localization in Preconfluent Endothelial Cells . . . 12

3.3 Myosin II and Actin Localization in Confluent Monolayers . . . . . . . . 19

3.4 Cell Attachment and Spreading . . . . . . . . . . . . . . . 22

3.5 Myosin IIA and Endothelial Cell Motility . . . . . . . . . . . 22

3.6 Effects of Myosin IIA on Isometric Tension . . . . . . . . . . . . . 27 
4 Discussion

References

33 


\section{List of Figures}

3.1 Dose-dependent experiment . . . . . . . . . . . . . . . . . . 10

3.2 Time-course experiment . . . . . . . . . . . . . . . . . . . 11

3.3 Confirmation of optimal condition for infection . . . . . . . . 12

3.4 Myosin IIA and actin localization in control cells . . . . . . . . . . . . 14

3.5 Myosin IIB and actin localization in control cells . . . . . . . . . . 15

3.6 Myosin IIA and actin localization in preconfluent cells infected with adshRNAi-IIA . . . . . . . . . . . . . . . . . 16

3.7 Myosin content in ad-shRNAi-IIA infected endothelial cells . . . . . . 17

3.8 Myosin IIB and actin localization in preconfluent cells infected with adshRNAi-IIA . . . . . . . . . . . . . . . . . 18

3.9 Double staining for myosin IIA and myosin IIB . . . . . . . . . . . 19

3.10 Myosin IIA and actin localization of control and ad-shRNAi-IIA infected confluent monolayers . . . . . . . . . . . . . . . . 20

3.11 Myosin IIB and actin localization of control and ad-shRNAi-IIA infected confluent monolayers . . . . . . . . . . . . . . . . 21 21

3.12 Endothelial cell attachment and spreading . . . . . . . . . . . 23

3.13 Motility of control cells . . . . . . . . . . . . . . . 25

3.14 Motility of ad-shRNAi-IIA infected cells . . . . . . . . . . 26

3.15 Effect of ad-shRNAi-IIA infection on myosin IIA content . . . . . . . . . 27

3.16 Path of cell movement . . . . . . . . . . . . . . . . 28

3.17 Force measurement of control and ad-shRNAi-IIA infected cells . . . . . 29 


\section{List of Tables}

3.1 Quantification of cell motility ................ 24 


\section{DOC Deoxycholic Acid \\ ECIS Electric Cell-substrate Impedance Sensing \\ MEM Minimal Essential Media \\ Glossary \\ MHC Myosin heavy chain \\ MLC Myosin light chain \\ MLCK Myosin light chain kinase}

Ad-shRNAi-IIA adenovirus encoding hairpin short interfering RNA targeting mouse non-musle Myosin IIA

DMEM Dulbecco's Modified Eagle Media
Myosin IIA Nonmuscle Myosin IIA

Myosin IIB Nonmuscle Myosin IIB

SVEC Mouse vascular endothelial cell 


\section{Chapter 1}

\section{Introduction}

The vascular system is lined by a continuous sheet of endothelial cells. The individual endothelial cell is typically a flattened, extended polygonal cell which interfaces with its multiple neighbors through a modest variety of junctional specializations characteristic of its site in the circulation. In vivo, the flattened state of cell abutted to cell is the usual condition. However, under the influence of a variety of stimuli, sizable gaps form between endothelial cells allowing the passage of large molecules otherwise confined to the circulation [1 4]. Evidence that the opening of endothelial cell junctions depending on an active contractile process was first presented by Majno and Palade [5]. These investigators observed in stimulated post-capillary venules that the endothelial cells bulged into the lumen and their nuclei developed numerous superficial pleats. Majno also observed that the endothelial cells expressed a prominent array of fine cytoplasmic filaments, which he proposed could generate the required contractile force [1,5]. This evidence provided a basis for the theory of endothelial cell contractility, while it need further support. In the early 80's several laboratories demonstrated gap formation between cultured endothelial cells upon exposure to thrombin [6] 8]. Rotrosen et al. [9] extended the observation to histamine while Shasby et al. 10 described a more severe retraction when endothelial cells were exposed to cytochalasin B. Furthermore, cytokines also induce gap formation that appears indistinguishable from histamine and thrombin.

Our laboratory has reported on the formation of gaps between endothelial cells induced by ethchlorvynol, an agent capable of increasing pulmonary capillary permeability and causing pulmonary edema [2,11]. We extended our studies to show similar 


\section{INTRODUCTION}

effects with histamine, thrombin and PAF 12 14. In our studies, the shape change is reversible and there is no injury to the cells. We have also shown that the change in Factin associated with shape change of the endothelial cell occurs in an ATP-dependent manner [15]. Our laboratory used the term retraction initially to avoid any a prior implication that it requires actomyosin-mediated contractile event. However, we now know from our permeabilized cell studies $[12,15]$ and from intact preparations $13,14,16$ that endothelial cells possess a myosin light chain kinase (MLCK) controlled contractile mechanism. Our laboratory has published a method that allows quantitative measurements of contractile force generated by cells grown within a collagen gel or by cells grown on top of a collagen matrix [14]. We have utilized the phosphorylation hypothesis as a prototype to study the mechanism of endothelial cell contractility [12, 17]. Endothelial cells do not appear to contract in the sense of shortening along a single axis as smooth muscle cells do. Instead, peripheral regions of the polygonal cell focally withdraw leaving spaces between adjacent cells which typically remain connected by tenuous processes $11,12,15,17$. Clues to the mechanism of contraction of endothelial cells have been provided by such diverse cell types as smooth muscle cells 18 21 fibroblasts $13,22,24$ RBL cells 25,26 and leukocytes 27]. Smooth muscle cells, unlike endothelial cells, contract in a polarized fashion.

The common event causing the stimulation of smooth muscle contraction is the increase in cytosolic free $\mathrm{Ca}^{2+}$. According to the simplest proposed model, $\mathrm{Ca}^{2+}$ associates with calmodulin and this complex activates MLCK which in turn results in phosphorylation of myosin light chain (MLC) thus initiating contraction 21,28. The phosphorylation of the $20 \mathrm{kD}$ MLC results in activation of the actin activated $\mathrm{Mg}$ ATPase activity of myosin which allows myosin to hydrolyze ATP and affect the transformation of chemical energy to mechanical work. Our permeabilized monolayer studies strongly implicated MLCK and MLC phosphorylation as the mechanism responsible for initiation of endothelial cell retraction. Our laboratory as well as Garcia's utilizing thrombin [29] and studies from Shasby's laboratory [30 with histamine have confirmed that stimulation with inflammatory agonists induces MLC phosphorylation.

Myosin light chain kinases are serine/threonine kinases that specifically catalyze the phosphorylation of serine-19 (Ser19) and threonine-18 (Thr18) in the $20 \mathrm{kD}$ regulatory light chain of myosin II 31 33. Phosphorylation of myosin light chain by MLCK is responsible for initiation of contraction in smooth muscle and leads to potentiation of 
contraction in skeletal muscle 34, 35] . However, the function of MLCK and myosin II in the control of nonmuscle contractility is not well understood. In vitro studies have suggested that MLCK may control the activity of nonmuscle myosin in nonmuscle cells. Phosphorylation of Ser19 by MLCK regulates both filament formation 14, 32, 36, and the myosin II actin activated ATPase activity 18,33] while diphosphorylation of MLC at both Ser19/Thr18 by MLCK has been implicated in increased filament stability and has been shown to further increase myosin II ATPase activity in vitro [37] .

So far, investigated vertebrates appear to contain three different isoforms of the conventional nonmuscle myosin II, designated as nonmuscle myosin IIA, myosin IIB and myosin IIC [38,39]. Although the precise functions of these myosins are not well understood, the mRNA encoding each isoform appears to be consistently expressed across many tissue and cell lines $40 \sqrt{42}$. Since these isoforms are regulated by phosphorylation of the $20 \mathrm{kD}$ light chains, it is plausible that differential targeting of isoform phosphorylation dictates unique cellular distributions and/or functions. It has been well known that myosin IIA is involved in the generation of contraction in nonmuscle cells and this process requires the actin cytoskeleton, specifically the localized polymerization of actin filaments. Myosin IIA is a potent motor protein responsible for cell contraction, but the specific molecular mechanisms are poorly understood.

Recent study indicates that endothelial barrier integrity depends on the actin and myosin cytoskeleton 43, 44. One possible mechanism of increase of vascular permeability is endothelial cell contraction. However, it is not completely understood how myoactin cytoskeleton is involved in endothelial cell contraction and results in an alteration in cell permeability. Understanding the molecular mechanisms of myosin IIA function in endothelial cells will identify novel therapeutic targets for human diseases that arise due to defects in endothelial barrier integrity.

In this study, the subject is to explore the role of nonmuscle myosin IIA in endothelial cell by knocking down nonmuscle myosin IIA expression in mouse vascular endothelial cells. 


\section{Chapter 2}

\section{Materials And Methods}

\subsection{Cell Culture and Reagents}

Mouse endothelial cell line obtained from mouse lung tissue was a generous gift of Dr. Troy Stevens, University of South Alabama.

Cells were cultured in minimal essential media (MEM) supplemented with $10 \%$ heat-inactivated fetal bovine serum, $50 \mathrm{unit} / \mathrm{ml}$ penicillin and $50 \mu \mathrm{g} / \mathrm{ml}$ streptomycin at $37^{\circ} \mathrm{C}$ under the humidified atmosphere of $5 \% \mathrm{CO}_{2}$ and $95 \%$ air. Cells were split at a ratio of 1:4 every 7-8 days.

\subsection{Immunofluorescence Microscopy}

Control and infected endothelial cells were washed with pre-warmed PBS 3 times, fixed with freshly made $37^{\circ} \mathrm{C}$ fixative (1\% formaldehyde in stabilization buffer, $\mathrm{pH} 6.5$ ) for 1 minute at $37^{\circ} \mathrm{C}$, followed by incubation with fixation and permeabilization buffer $(2 \%$ formaldehyde, $0.2 \%$ triton X-100, $0.5 \%$ DOC in stabilization buffer, $\mathrm{pH} 6.5$ ) for 1 hour at $37^{\circ} \mathrm{C}$. Before staining, cultures were washed once with PBS and then permeabilized in stablization buffer containing $0.5 \%$ triton X-100, 0.6\% DOC, pH 6.5 for 10 minutes at room temperature. After permeabilization, cell cultures were washed with PBS 3 times and flooded with $2 \mathrm{ml}$ of blocking buffer (PBS containing 0.8\% BSA, 0.5\% fish gelatin, $10 \mu \mathrm{g} / \mathrm{ml} \mathrm{IgG)} \mathrm{for} 1$ hour. Blocking buffer was removed and cultures were incubated with primary antibody in diluted blocking buffer (1:10 dilution) for 3 hours at room temperature. After primary antibody incubation, cell cultures were washed with diluted blocking buffer and then incubated with secondary antibody in diluted 
blocking buffer for 2 hours at room temperature. Cultures were washed 3 times with PBS and coversliped with $90 \%$ glycerol/10\% PBS containing $0.1 \mathrm{M}$ n-propyl gallate. Pictures were taken on a Zess 510 confocal microscope and Z series images were built into composite micrographs.

For staining of myosin IIA + actin or myosin IIB + actin, myosin IIA or myosin IIB were stained in $0.25 \mu \mathrm{g} / \mathrm{ml}$ affinity purified rabbit polyclonal anti-myosin IIA or anti-myosin IIB primary antibody and followed by Alexa 488 labeled goat anti rabbit secondary antibody. Actin filaments were stained with $1.0 \mu \mathrm{g} / \mathrm{ml}$ rhodamine phalloidin (Sigma, Cat No. P1591) for 1 hour at room temperature. For double staining of myosin IIA + myosin IIB, myosin IIA was stained with $1.0 \mu \mathrm{g} / \mathrm{ml}$ working concentration of rabbit polyclonal anti-myosin IIA, followed by Alexa 488 labeled donkey anti rabbit secondary antibody. Myosin IIB was stained with $1.5 \mu \mathrm{g} / \mathrm{ml}$ working concentration of affinity purified goat polyclonal primary antibody, followed by Alexa 568 labeled donkey anti goat secondary antibody.

\subsection{Virus Amplification}

Adenovirus encoding short hairpin interfering RNA targeting a mouse nonmuscle myosin IIA (shRNAi-IIA) was amplified in $293 \mathrm{~T}$ cells. Cells were seeded into T75 $\mathrm{cm}^{2}$ flask 24 hour prior to infection. After achieving 70-80\% confluence, 293T cells were washed 3 times with serum free MEM media without penicillin/streptomycin, incubated with media containing virus at $37^{\circ} \mathrm{C}$ for 2 hours. After infection, cell cultures were fed with media (without penicillin/streptomycin) with $10 \%$ fetal bovine serum and incubated at $37^{\circ} \mathrm{C}$. After most of the cells become round (about 24 hours post infection), cells were dislodged by pipeting up and down, media and cells were collected and spun down at $1000 \times \mathrm{g}(2000 \mathrm{rmp}), 4^{\circ} \mathrm{C}$ for 20 minutes. Cell pellets were re-suspended in $5 \mathrm{ml}$ of sterile $100 \mathrm{mM}$ Tris buffer (pH8). Cell pellets were frozen in a dry-ice-methanol slurry and immediately thawed in a $37^{\circ} \mathrm{C}$ water bath. Cell pellets were processed through 3 freeze-thaw cycles. Cell lysates were spun down at $1000 \times \mathrm{g}(2000 \mathrm{rpm})$ at $4{ }^{\circ} \mathrm{C}$ for 20 minutes, supernatant was saved and pellet was discarded. 


\section{MATERIALS AND METHODS}

\subsection{CsCl Purification}

CsCl gradients were prepared in SW-40T tubes (Beckman ultra clear tubes, Cat344059): First, $2.12 \mathrm{ml}$ of $12 \mathrm{~g} / \mathrm{cc} \mathrm{CsCl} \mathrm{(26.8} \mathrm{g} \mathrm{CsCl} \mathrm{in} 92 \mathrm{ml}$ of $100 \mathrm{mM}$ Tris buffer PH 8, $10 \mathrm{mM}$ EDTA) was placed at bottom of SW-40T tube. Then $\mathrm{CsCl}$ layer containing $2.82 \mathrm{ml}$ of $1.4 \mathrm{~g} / \mathrm{cc} \mathrm{CsCl}$ (53 g CsCl in $87 \mathrm{ml}$ of $100 \mathrm{mM}$ Tris $\mathrm{pH} 8,10 \mathrm{mM}$ EDTA) was pipeted onto the top of $12 \mathrm{~g} / \mathrm{cc} \mathrm{CsCl.} 7 \mathrm{ml}$ viral supernatant was gently added on top of $\mathrm{CsCl}$ cushion and spun down at $210,000 \times \mathrm{g}(35,000 \mathrm{rmp})$ at $4{ }^{\circ} \mathrm{C}$ for $1 \mathrm{hr}$ in the $\mathrm{SW}-40 \mathrm{Ti}$ rotor, by using max-start and low brake.

After centrifugation, two distinct bands form the $\mathrm{CsCl}$ gradient interfaces. The bottom band which is white and fluffy at the interface between the $1.4 \mathrm{~g} / \mathrm{cc}$ and 1.2 $\mathrm{g} / \mathrm{cc}$ layers was collected with an $18 \mathrm{G}$ gauge needle attached to a $5 \mathrm{ml}$ sterile syringe. The tube was punctured below the band for withdrawing only the viral particles.

A second $\mathrm{CsCl}$ gradient in polyallomar quick seal tubes was prepared (Beckman 13x51mm, Cat342412).

Tubes were placed on ice and virus was added to the bottom of each tube, then $1.34 \mathrm{~g} / \mathrm{cc}(13.5 \mathrm{~g}$ of $\mathrm{CsCl}$ in $30 \mathrm{ml}$ of $100 \mathrm{mM}$ Tris buffer $\mathrm{pH} 8,10 \mathrm{mM}$ EDTA) was added to the top of the dome.

Sealed tubes were spun at $320000 \times \mathrm{g}(60,000 \mathrm{rmp})$ at $4{ }^{\circ} \mathrm{C}$ overnight (more than 8 hours) in the rotor VTi65.2.

PD10 columns (PD10 sephadex G25, pre-packed column) were washed twice with $25 \mathrm{ml}$ of sterile $30 \%$ glycerol in PBS. After removing tubes from centrifuge, the top of each tube was punctured to release pressure. A white and fluffy band containing virus was collected with an $18 \mathrm{G}$ gauge needle attached to a $5 \mathrm{ml}$ sterile syringe.

Virus was placed on PD-10 column. $10 \mathrm{ml}$ of $30 \%$ glycerol/PBS solution was added to the column, and $500 \mu \mathrm{l}$ fractions were collected. All samples were analyzed by using Nanodrop spectrophotometers at OD $260 \mathrm{~nm}$ to determine which fraction contain purified virus. Virus was stored at $-80^{\circ} \mathrm{C}$.

\subsection{Adenovirus Infection}

50,000 cells were seeded onto $35 \mathrm{~mm}$ dish pre-coated with $20 \mu \mathrm{g} / \mathrm{ml}$ collagen 24 hours before infection. For each infected dish, cell cultures were incubated with 1ml MEM media containing adenovirus (without penicillin/streptomycin and serum) for 2 hours 
at $37^{\circ} \mathrm{C}$, then fed with $1 \mathrm{ml}$ MEM media (without penicillin/streptomycin) plus $20 \%$ fetal bovine serum. After 48 hours, old media was removed and cultures were fed with fresh MEM media (without penicillin/streptomycin) with $10 \%$ fetal bovine serum containing same amount of adenovirus as initial infection. The total infection duration was 96 hours.

\subsection{Western Blot Analysis}

Cell cultures were washed 3 times with PBS before harvest. Each culture dish was flooded with $100 \mu \mathrm{l}$ of $100^{\circ} \mathrm{C} 1.5 \times$ SDS sample buffer containing $10 \mu \mathrm{g} / \mathrm{ml}$ DNase I. Cells were collected by scraping from the dish with a rubber policeman and transferred to microfuge tubes.

Cells were sonicated and heated at $100{ }^{\circ} \mathrm{C}$ for 10 minutes to denature proteins and samples were stored frozen at $-80^{\circ} \mathrm{C}$.

SDS samples were run on $10 \%$ SDS-PAGE gels and then transferred to PVDF membrane. $0.1 \%$ SDS was included in transfer buffer to help facilitate protein transfer.

Membranes were incubated with the affinity purified primary antibodies against NMHC IIA (rabbit polyclonal anti-myosin IIA, $0.025 \mu \mathrm{g} / \mathrm{ml}$ ), NMHCIIB (rabbit polyclonal anti-myosin IIB, $0.025 \mu \mathrm{g} / \mathrm{ml}$ ), and GAPDH (Sigma, Cat. No. G8795, mouse monoclonal, 1:10,000 dilution) at room temperature for 3 hours, followed by incubation with horseradish peroxidase-conjugated secondary antibodies at 1:5000 dilution (goat anti rabbit) at room temperature for 1 hour. The immunoblotted proteins were incubated with ECL reagent and exposed to X-ray film.

\subsection{Isometric Tension Measurements}

Cells were resuspended in appropriate amount of collagen solution containing fibrinogen $(1 \mathrm{mg} / \mathrm{ml}$ rat tail collagen I, $3 \mathrm{mM} \mathrm{NaOH}, 0.2 \mathrm{mg} / \mathrm{ml}$ fibrinogen in DMED media plus $10 \%$ fetal bovine serum) to achieve final concentration of $1 \times 10^{6} \mathrm{cell} / \mathrm{ml} . \quad 2$ unit/ml thrombin was added to collagen/cell suspension before being poured into a Teflon mold with central pole. Molds were incubated at $37^{\circ} \mathrm{C}$ for 2 hours to allow collagen polymerization, which initiated the collagen/cell matrix forming a ring. 


\section{MATERIALS AND METHODS}

Molds were fed with MEM media (with penicillin/streptomycin) plus $10 \%$ fetal bovine serum 2 hours after casting and incubated at $37^{\circ} \mathrm{C}$ for 24 hours prior to adenoviral infection.

After 24 hours, collagen/cell gels were washed twice with MEM media without penicillin/streptomycin and serum before being infected with adenovirus within molds. For each infected mold, collagen/cell rings were infected by incubating with $1 \mathrm{ml}$ adenoviruscontaining MEM media (without penicillin/streptomycin and serum) for 2 hours at $37^{\circ} \mathrm{C}$. Molds were then fed with $2 \mathrm{ml}$ MEM media (without penicillin/streptomycin) plus $15 \%$ fetal bovine serum. After 48 hours infection, media were replaced with fresh MEM media (without penicillin/streptomycin) with $10 \%$ fetal bovine serum plus same amount of adenovirus as initial infection and incubated at $37^{\circ} \mathrm{C}$. Infections were carried out for a total of 96 hours. After 96 hours incubation, the collagen/cell rings were removed from molds and hanged on isometric force transducer (model 52-9545; Harvard Apparatus, South Natick, MA). Rings were bathed in $50 \mathrm{ml}$ HEPES-buffered MEM media supplemented with $10 \% \mathrm{BSA}$ in a thermoregulated bath at $37^{\circ} \mathrm{C}$ and $\mathrm{pH}$ 7.4. After baseline force was developed, cell rings were stimulated with 2 unit $/ \mathrm{ml}$ thrombin. After achieving stable tension, the cell rings were treated with $2 \mu \mathrm{M}$ cytochalasin D.

\subsection{Attachment and Spreading Measured by ECIS}

Control or infected cells were seeded onto ECIS cultureware (100,000 per well, $0.8 \mathrm{~cm}^{2}$ per well) pre-coated with collagen $(5 \mu \mathrm{g} /$ well). The ECIS measurement was started immediately after cells were seeded into chambers. Cells attached and spread on the small gold electrode on the bottom of the chamber. A current passed between the small gold-film electrode and a larger gold counterelectrode. As cultured cells attach and spread onto the electrodes, the current has to flow in the spaces under and between the cells which causes the increase in the electrical resistance, as the cell membrane is essentially an insulator. The total time duration of measurement is 24 hours.

\subsection{Cell Motility}

Control or infected cells were seeded onto $35 \mathrm{~mm}$ dish (50,000 per dish) and subjected to cell motility measurement by Nikon Swep Field confocal system 24 hours after cast- 
ing. The total time duration of measurement is 5.5 hours. The centroid position $(x, y)$ of each cell was tracked at each 60 -second interval for the entire duration of the experiment. Cells that migrated out of the image field as well as divided during the experiment were excluded from the calculation. The speed of migrating cell was calculated by using the distance that the centroid position of the cell moved over each 30 minute interval. 


\section{Chapter 3}

\section{Results}

\subsection{Adenovirus Infection}

In order to determine the optimal condition for reducing the level of myosin IIA in mouse endothelial cells, experiments were undertaken to assess the appropriate incubation dose and time needed to reduce nonmuscle myosin IIA using adenovirus encoding an shRNAi to nonmuscle myosin IIA in cells.

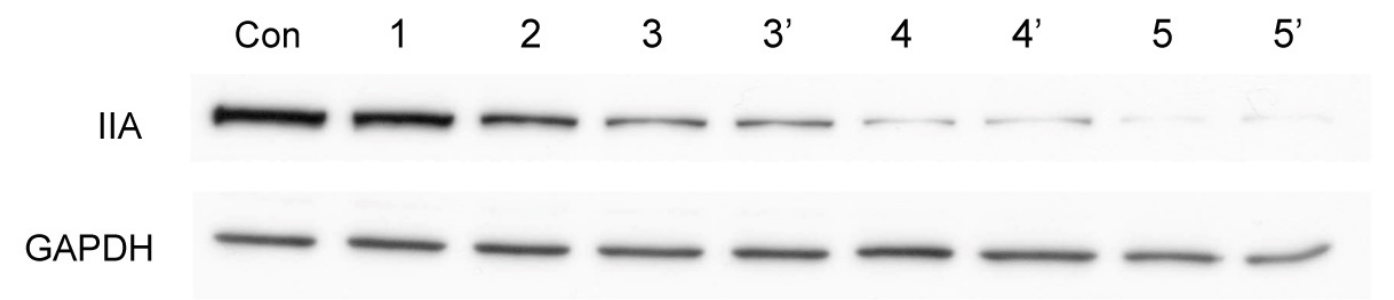

Figure 3.1: Dose-dependent experiment - Figure presents the result of western blot of cell lysate from mouse endothelial cell cultures infected with different amount of adshRNAi-IIA (1=MOI 12.5 per cell, 2=MOI 25 per cell, 3, 3'=MOI 50 per cell, 4, 4'=MOI 100 per cell, 5, 5'=MOI 200 per cell, prime indicates duplicate loading). Increasing virus dosage resulted in a steady decrease in myosin IIA expression reaching maximal myosin IIA knockdown at MOI 100 per cell.

Figure 3.1 is a representative western blot of cell lysate from mouse endothelial cell cultures infected with different amount (MOI 12.5 per cell, MOI 25 per cell, MOI 50 per cell, MOI 100 per cell, MOI 200 per cell) of adenovirus encoding sh-RNAi-IIA. Western Blots were probed with affinity purified antibody to myosin IIA. As shown in figure 1, 
the shRNAi-IIA probe is effective in reducing endogenous endothelial cell myosin IIA. Low dosage of virus had a minimal effect on myosin IIA levels, while increasing doses resulted in a steady decrease in myosin IIA, reaching maximal IIA knockdown at MOI 100 per cell. For quantitative analysis, the myosin IIA knockdown was ratioed to the level of GAPDH in cell extracts.

Myosin IIA levels were reduced by $26 \%$ in cultures incubated with MOI 12.5 per cell, $56 \%$ in cultures incubated with MOI 25 per cell and $62 \%$ in cultures incubated with MOI 50 per cell, while in cultures incubated with MOI 100 per cell and MOI 200 per cell a maximal $82 \%$ reduction occured. From these results, a dose of MOI 100 per cell ad-shRNAi-IIA was chosen for use in all experiments.

After establishing the appropriate dose, experiment was undertaken to determine the time duration for maximal reduction of myosin IIA levels. Mouse endothelial cells were infected with MOI 100 per cell for 48 hours, 72 hours and 96 hours. After appropriate time intervals, both control and infected cell cultures were harvested, and cell lysates were analyzed by western blot for myosin IIA expression level.

After 48 hours incubation with virus, the myosin IIA level was reduced by $48 \%$. Further increasing the incubation time to 72 hours and 96 hours, we achieved a reduction in myosin IIA of $71 \%$ and $81 \%$ respectively (figure 3.2 ). Maximal reduction of myosin IIA occurred after 96 hours incubation with ad-shRNAi-IIA.

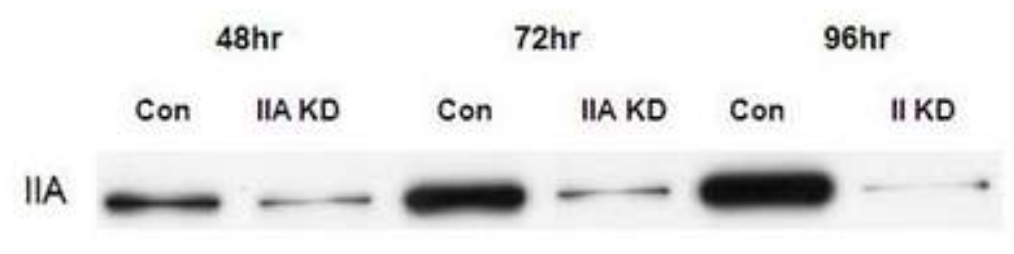

Figure 3.2: Time-course experiment - Mouse endothelial cells were infected with MOI 100 per cell for $48 \mathrm{hrs}, 72 \mathrm{hrs}$ and $96 \mathrm{hrs}$. Western blot of cell lysates from mouse endothelial cell cultures showed maximal reduction of myosin IIA occurred after $96 \mathrm{hrs}$ incubation with ad-shRNAi IIA.

To confirm the dose response and time course experiments, cells were infected with a dose of MOI 100 per cell for 96 hour. Cells lysates were analyzed by western blot as shown in Figure 3.3 . 
A

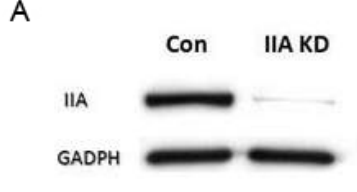

B

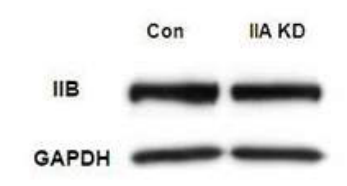

Figure 3.3: Confirmation of optimal condition for infection - Mouse endothelial cells were infected with a dose of MOI 100 per cell for 96 hour and a 90\% reduction in myosin IIA content occurred in respond.

After 96 hours, a 90\% reduction in myosin IIA content occurred in respond to a dose of MOI 100 per cell as shown in figure 3.3 A.

Since myosin IIA and myosin IIB heavy chains have similar structural characteristics, cell lysates were probed with affinity purified myosin IIB antibody to ensure that our IIA probe had no effect on myosin IIB content. As shown in figure $3.3 \mathrm{~B}$, incubation of cells with adnovirus encoding shRNAi-IIA had no effect on myosin IIB content while reducing myosin IIA levels by $90 \%$ (figure $3.3 \mathrm{~B}$ ).

\subsection{Myosin II and Actin Localization in Preconfluent En- dothelial Cells}

It's well-known that nonmuscle myosin II and F-actin have a fundamental role in regulating cell shape, motility and force development. In tissue culture dishes preconfluent endothelial cells assume various shapes with different cytoskeletal organization. As cells grow, divide and contact one another, their cytoskeleton continuously changes until reaching a stable configuration 5-6 day after being seeded onto culture dishes. At confluence endothelial cells form a sheet of polygonal cells tightly attached to one another forming a semi-permeable membrane that regulates the movement of solutes across the monolayer. Since, endothelial cells change shapes as they grow, we sought to determine the structural differences in myosin II and actin organization in endothe- 
lial cells 24 hours after seeding from endothelial cells within a confluent monolayer 5 day post seeding. Figure 3.4 illustrates the distribution of myosin IIA and actin and figure 3.5 myosin IIB and actin within representative cell morphologies identified in culture. Actin filaments for the most part were bundled into stress fibers that ran parallel to the long axis of the cell. In one group of cells (Fig. 3.4 A and 3.5 A) there was a complex array of paranuclear actin filaments with small filaments emanating radialy for this complex. In a second group (Fig. $3.4 \mathrm{~B}$ and $3.5 \mathrm{~B}$ ) the actin filamants varied in length, ran parallel to one another but had no paranuclear actin complex. In the last group identified Fig. $3.4 \mathrm{C}$ and $3.5 \mathrm{C}$ actin filaments appeared to arise from a paranuclear array of filaments and coursed toward the periphery of the cell in a radial spoke like pattern. Both myosin IIA (Fig. 3.4) and IIB (Fig. 3.5) were associated with the underlying actin filaments however myosin IIA was more concentrated within the paranuclear actin arrays.

To determine if myosin IIA has a role in forming and maintaining these structures, experiments were undertaken to knock down myosin IIA in endothelial cells and determine what effects loss of myosin IIA had on the cellular cyto-architecture. Endothelial cells were infected with a adenovirus encoding a shRNAi to myosin IIA, cells were harvested 96 hours post infection and seeded at preconflunet densities fixed 24 hrs after seeding and stained for either myosin IIA/actin (Fig. 3.6) or myosin IIB/actin (Fig. 3.8 staining. Parallel dishes were harvested for SDS gels analysis to determine the extent of myosin IIA knock down (Fig. 3.7A) and to show shRNA-IIA constructs did not alter myosin IIB protein levels (Fig. 3.7B). Treatment of cultures with our adenovirus encoding shRNAi-IIA at MOI 100 per cell resulted in 90\% reduction of myosin IIA with no significant affect on myosin IIB levels (Fig. 3.7B). Immunofluoresent localization studies showed major reductions in myosin IIA levels within all cells compared to controls (Fig. 3.4). However, the total amount of IIA loss varied somewhat from cell to cell. Two levels of NMHC-IIA knock down cells were identified. Fig. 3.6A illustrates a representative cell where negligible amounts of myosin IIA remain within the cytoplasm. The lingering myosin IIA is randomly dispersed throughout the cytoplasm taking on no distinct pattern. Cells with this phenotype were larger in size and display large protruding lamella from different regions of their cell body. Co-staining these cells with rhodamine phalloidin showed loss of NMHC-IIA has a striking effect on underlying actin stress fibers. The ordered stress fiber organization within the cytoplasm was 

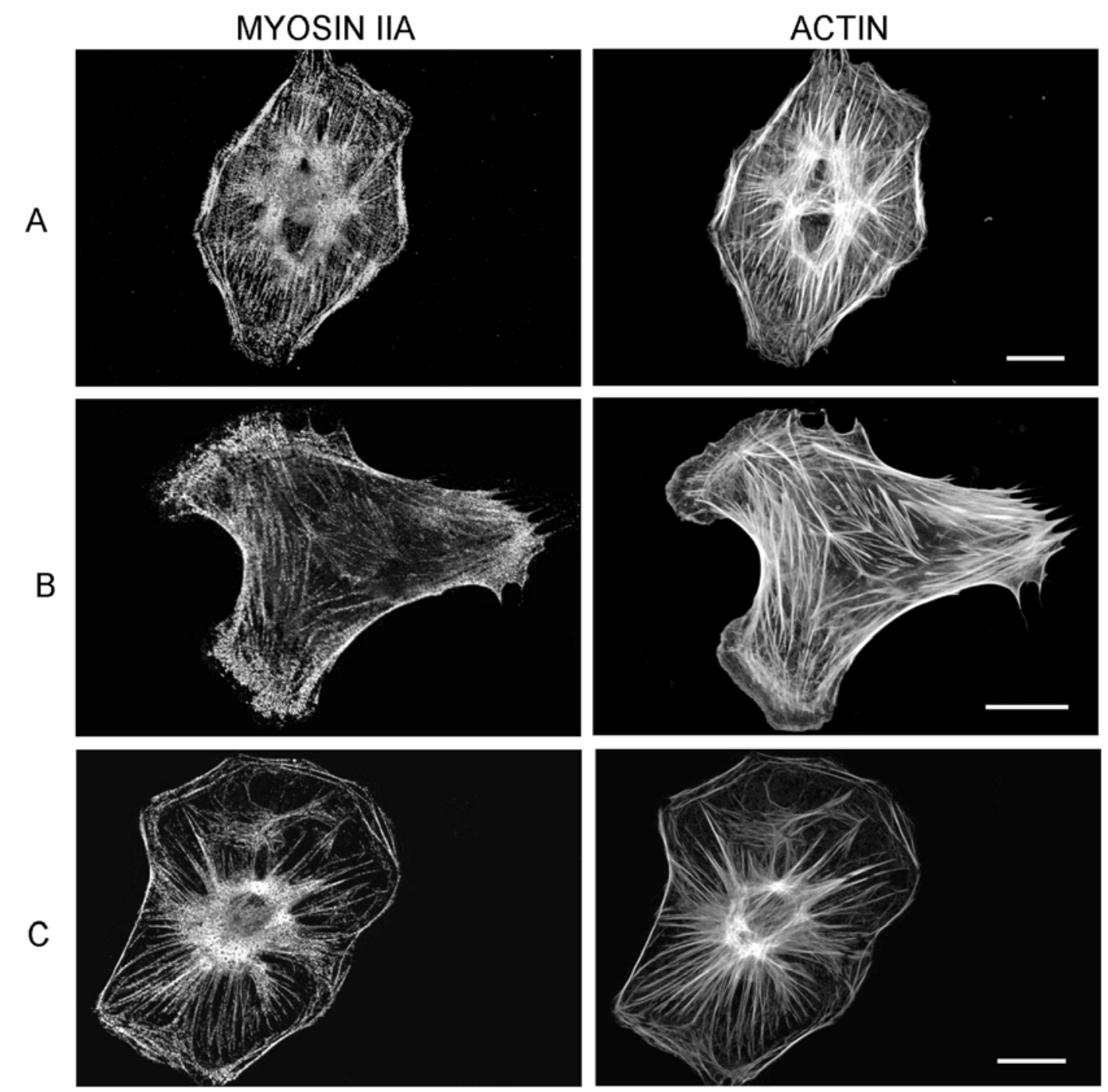

Figure 3.4: Myosin IIA and actin localization in control cells - Preconfluent endothelial cells were stained for myosin IIA and actin. Endothelial cells were fixed 24 hours post seeding. Bar, $20 \mu \mathrm{m}$. 

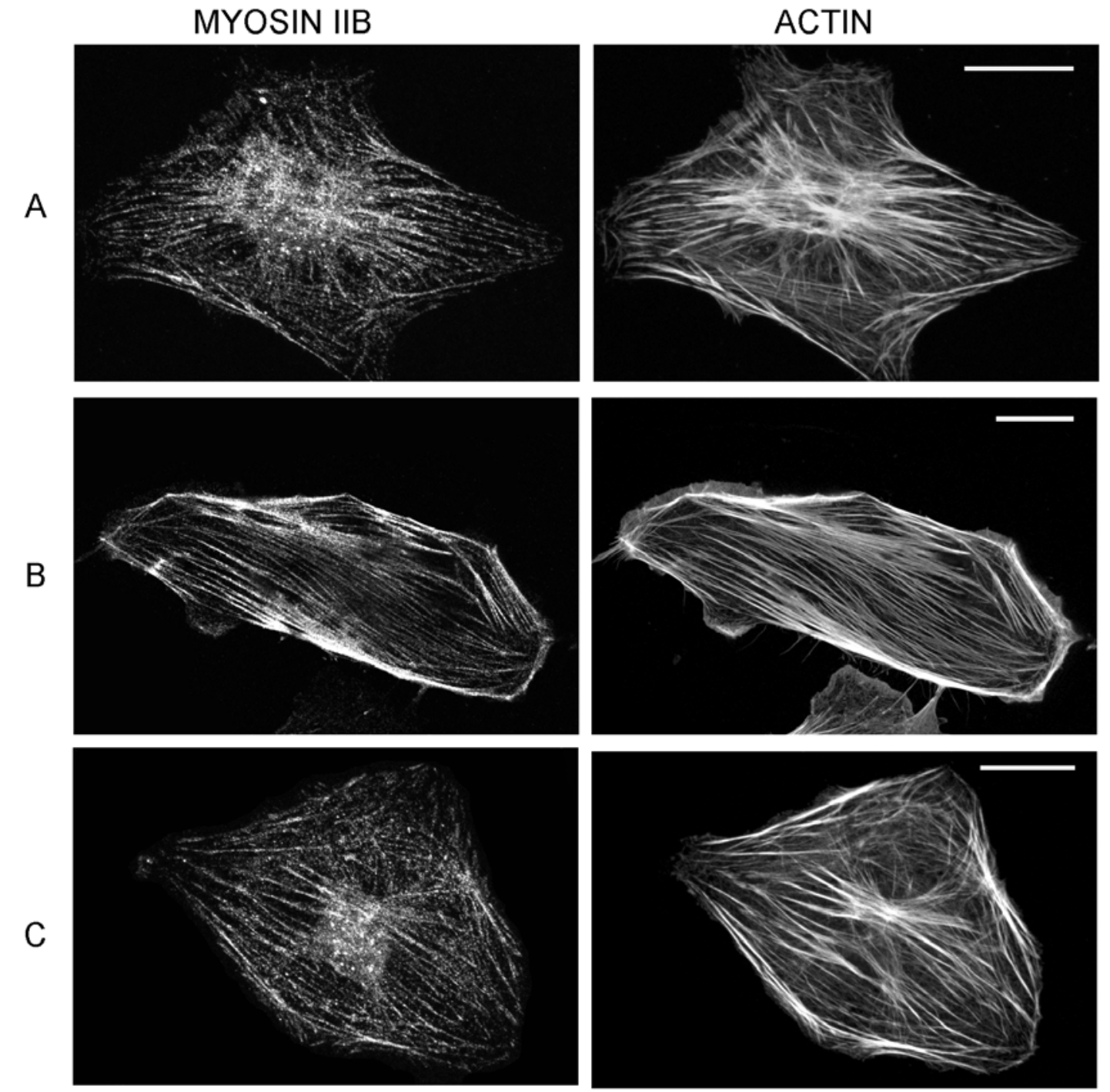

Figure 3.5: Myosin IIB and actin localization in control cells - Preconfluent endothelial cells were fixed 24 hours post seeding and stained for myosin IIB and actin. Bar, $20 \mu \mathrm{m}$. 
MYOSIN IIA
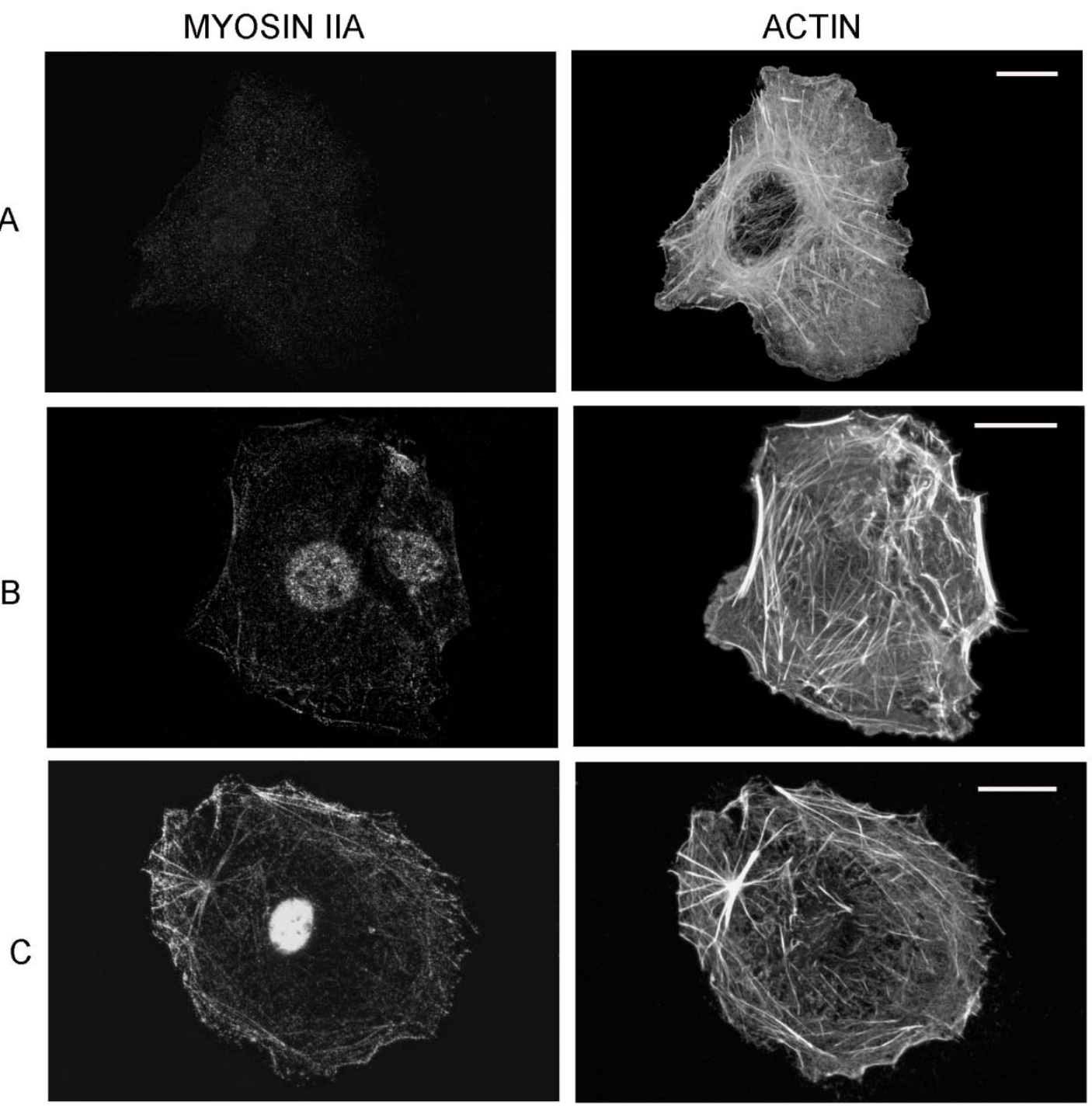

Figure 3.6: Myosin IIA and actin localization in preconfluent cells infected with ad-shRNAi-IIA - Loss of myosin IIA induced loss of stress fibers, which cause significant changes in actin organization and cell shape. Bar, $20 \mu \mathrm{m}$. 
A

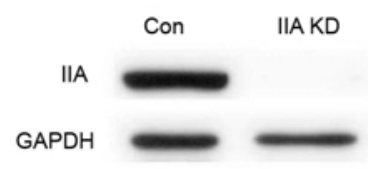

B

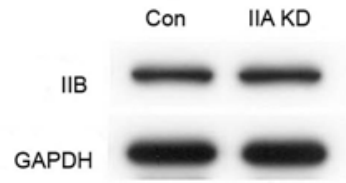

Figure 3.7: Myosin content in ad-shRNAi-IIA infected endothelial cells - Myosin II A level was dramatically decreased in ad-shRNAi IIA infected cells, while myosin IIB was not affected.

lost. Stress fiber that remain were short filaments randomly orientated concentrated near the nuclear region while membrane protrusions were filled with a fine reticular meshwork of actin filaments (Fig. 3.6A). The majority (>85\%) of infected cells exhibited this phenotype. About $15 \%$ of the cells observed still had detectable myosin IIA present within the cytoplasm. Myosin IIA localized at the cell periphery and associated with underlying actin filaments. Actin filament structure was disorganized, however, the number of actin filaments present in cells and the degree of disruption did not directly correlate with the extent of myosin IIA knock down. The content of myosin IIB minimally changed in NMHC-IIA knock down cells (Fig. 3.7B). Myosin IIB co-localized with the actin stress fibers and the fine actin meshwork that formed in myosin IIA knock down cells (Fig. 3.8A-C). These results confirmed the specificity of Ad-shRNAi knock down construct and showed that myosin IIB association with actin appeared unaltered in NMHC-IIA knock down cells.

In order to directly compare the localization of myosin IIA and myosin IIB in control and NMHC-IIA knockdown endothelial cells, cultures were fixed and double stained for myosin IIA and myosin IIB. As shown in figure 3.9 myosin IIA and myosin IIB exhibited a sarcomeric like distribution associated with the underlying actin filaments. This was the same distribution found in untreated control cells stained for myosin IIA/actin and 


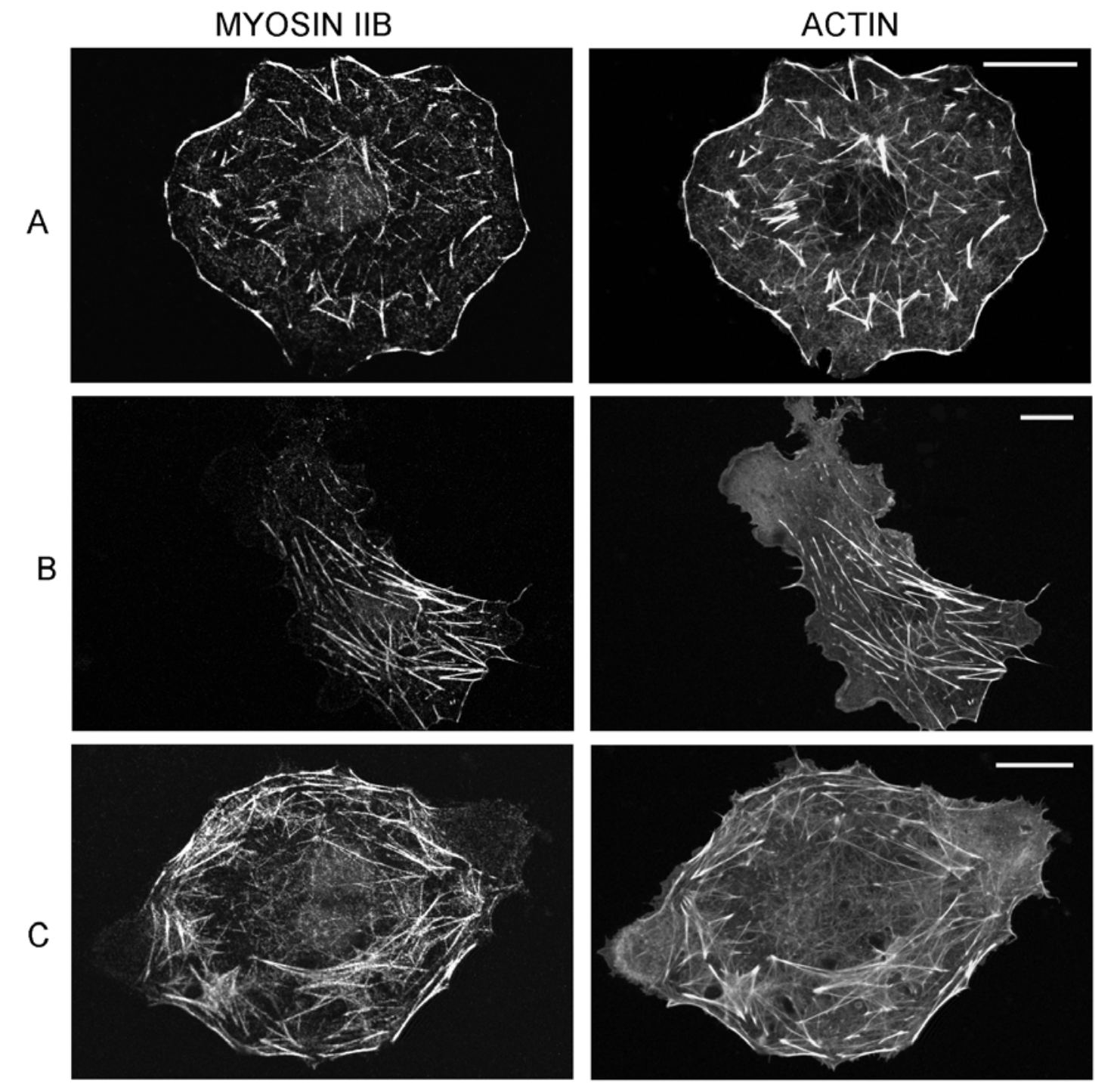

Figure 3.8: Myosin IIB and actin localization in preconfluent cells infected with ad-shRNAi-IIA - Cell shapes were changed dramatically while myosin IIB still associated with actin. Bar, $20 \mu \mathrm{m}$. 
IIB/actin alone (Fig. 3.4 and 3.6). NMHC-IIA knock down resulted in disruption but not complete loss of actin stress fibers. Myosin IIB associated with stress fibers as well as the fine actin network that formed within the cell cytoplasm. Staining for myosin IIA/IIB/actin in control and myosin IIA knockdown cultures confirmed our previous results.
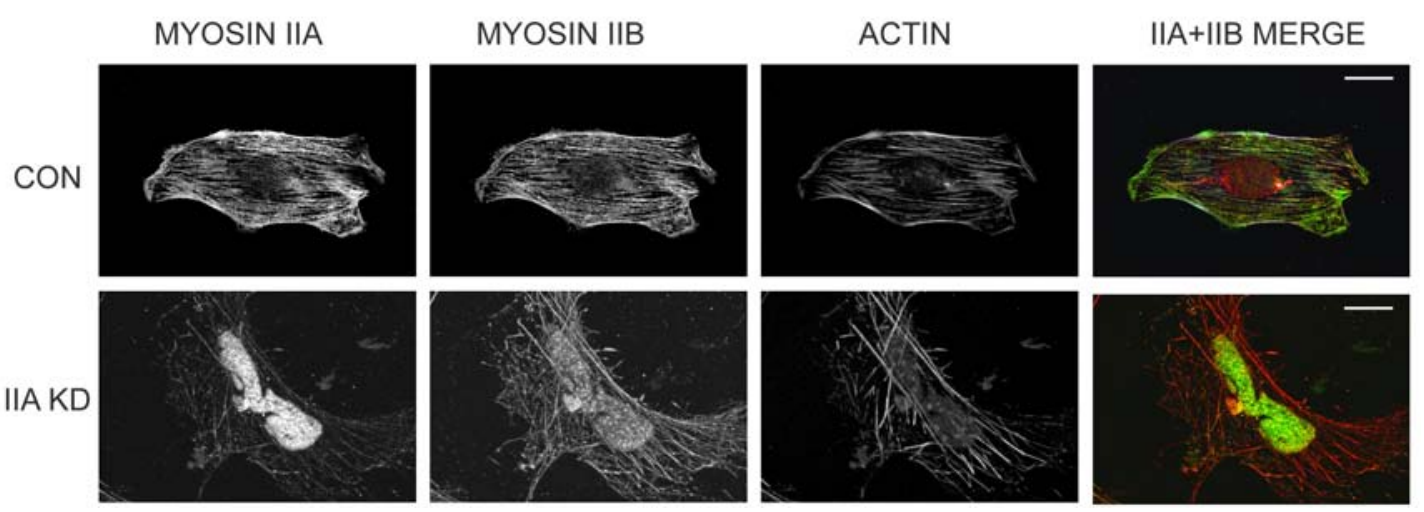

Figure 3.9: Double staining for myosin IIA and myosin IIB - Control and adshRNAi-IIA infected cells were double stained for both myosin IIA and myosin IIB (myosin II A is in green and myosin IIB is in red in merge picture). Bar, $20 \mu \mathrm{m}$.

\subsection{Myosin II and Actin Localization in Confluent Mono- layers}

Since the confluent endothelial cell monolayer is believed to be a model representative of endothelial cells lining blood vessels, we sought to determine if loss of myosin IIA alters endothelial cell monolayer cytoskeletal structure. Result from myosin IIA / actin staining of control and ad-shRNAi-IIA infected confluent endothelial monolayers is presented in figure 3.10. In untreated controls, myosin IIA was localized to the cell margins outlining individual cell within monolayers as well as within the cytoplasm as small droplets or rods like structures. F-actin concentrated at cell boarders and formed stress fibers throughout the cytoplasm. Loss of myosin IIA did not cause monolayers to lift off the culture dishes nor cause large gaps to form between individual cells. Besides a slight change in cell shape, monolayers appeared unaffected as examined by light microscopy. In contrast, monolayers infected with ad-shRNAi-IIA and stained for 


\section{RESULTS}

myosin IIA/actin showed loss of myosin IIA from the cell margins while small aggregates of myosin IIA staining material formed within the cytoplasm. The actin localization at the cell periphery was also lost while the cytoplasmic stress fibers appeared shorter and more disorganized. In control, monolayers myosin IIB localized to the boarders between cells similar to that seen with myosin IIA (Fig. 3.11). Small droplets of myosin IIB were also distributed throughout the cytoplasm. F-actin localized to the cell margins and central stress fibers and myosin IIB was found decorating their structures. In myosin IIA knocked down cells, myosin IIB appeared minimally altered. Myosin IIB remained localized at cell margins. However, myosin IIB appeared to associate more prominently with central stress fibers.

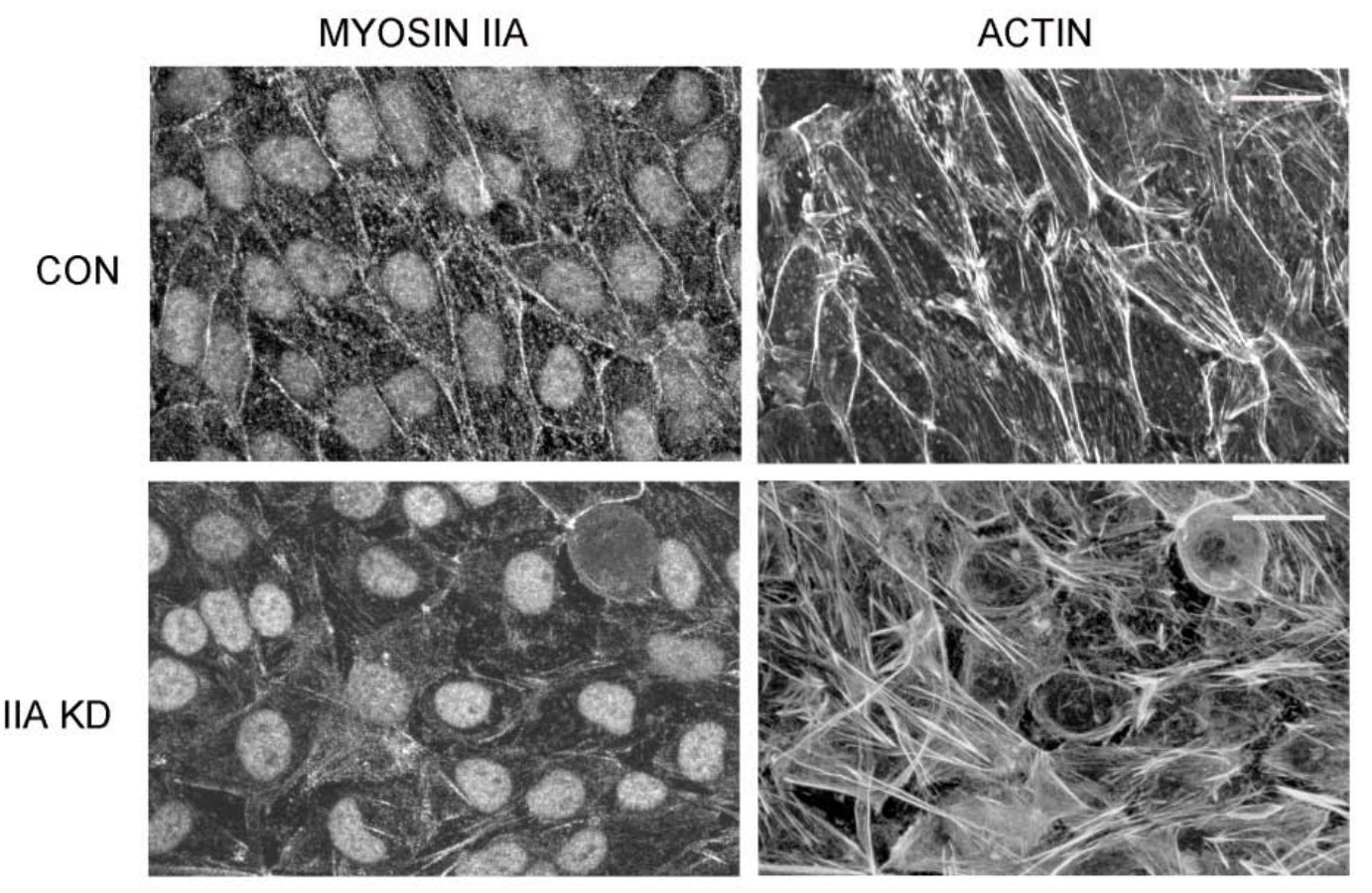

Figure 3.10: Myosin IIA and actin localization of control and ad-shRNAiIIA infected confluent monolayers - The result presented that loss of myosin at cell periphery affected organization of actin fiber. Bar, $20 \mu \mathrm{m}$. 

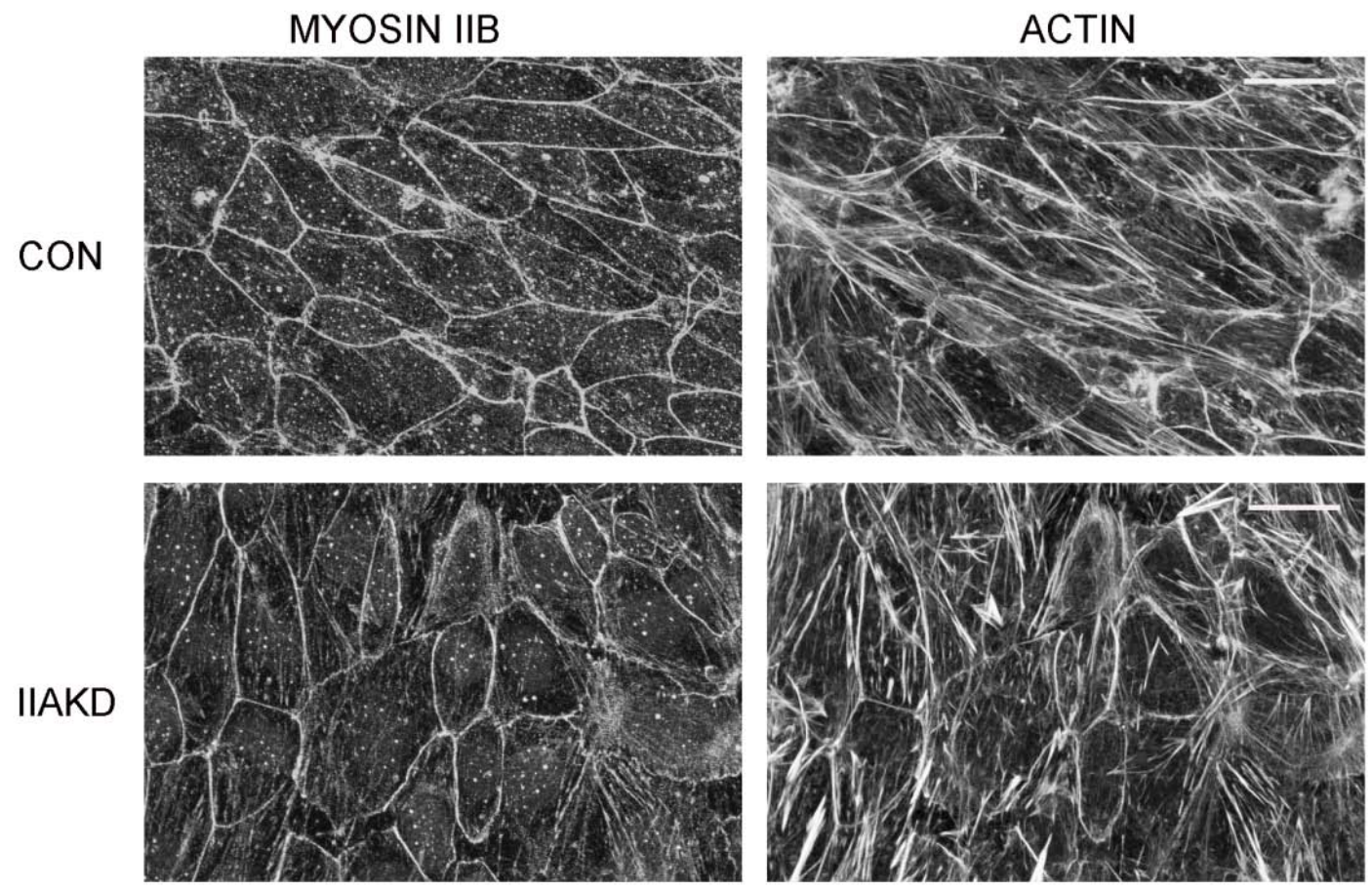

Figure 3.11: Myosin IIB and actin localization of control and ad-shRNAi-IIA infected confluent monolayers - Myosin IIB localization was not affected by loss of myosin IIA, even though cells appeared larger and more spread. Bar, $20 \mu \mathrm{m}$. 


\section{RESULTS}

\subsection{Cell Attachment and Spreading}

Knocking down of myosin IIA alter both the actin and myosin II cytoskeleton in both pre-confluent and post confluent endothelial cells. Since, the cytoskeleton is critical for cell attachment and spreading and we wanted to determine if reorganization of the cytoskeleton altered the rate and degree of endothelial cell attachment and spreading. For these experiments we used Electric Cell-substrate Impedance Sensing (ECIS) measurements to follow changes in cell attachment and spreading in control and infected endothelial cells.

Collagen coated ECIS culture chambers were placed in the ECIS apparatus. Control and ad-shRNA-IIA infected mouse endothelial cells were seeded into chambers and measurements started immediately. Figure 3.12 shows representative cell attachment and spreading tracings for control (uninfected), negative control (cell treated with non-targeting virus) and myosin IIA knockdown cells. No significant difference in cell adhesion was detected within the first 15 minutes. By 30 minutes, the myosin IIA knockdown cells showed a greater increase in electrical resistance suggesting that either more cells had adhered to the substratum or the myosin IIA knockdown cells spread faster. Myosin IIA knockdown cells continued to show an increase in resistance over the ensuing 12 hour compared to controls suggesting knockdown cells spread faster or were bigger than the control cells. After 12 hours, knockdown cells exhibited a stable resistance while the control cell lines continued to develop resistance, suggesting control cells were forming a tighter or more cohesive layer. These experiments suggested that loss of myosin IIA initially accelerated cell spreading allowing for greater coverage of the ECIS chamber and resulting in an increase in resistance compared to the paired controls. However, as the cells continued to spread/grow, it appeared that myosin IIA was needed for development of a cohesive endothelial cell monolayer.

\subsection{Myosin IIA and Endothelial Cell Motility}

Our result showed myosin IIA was involved in modulating cell adhesion and spreading, which were early events in cell migration. To determine the role of myosin IIA in endothelial cell migration, experiments were undertaken to directly measure the rate of endothelial cell movement in control and myosin IIA knockdown endothelial cells. 50,000 control or myosin IIA knockdown cells were seeded onto dishes and allowed to 


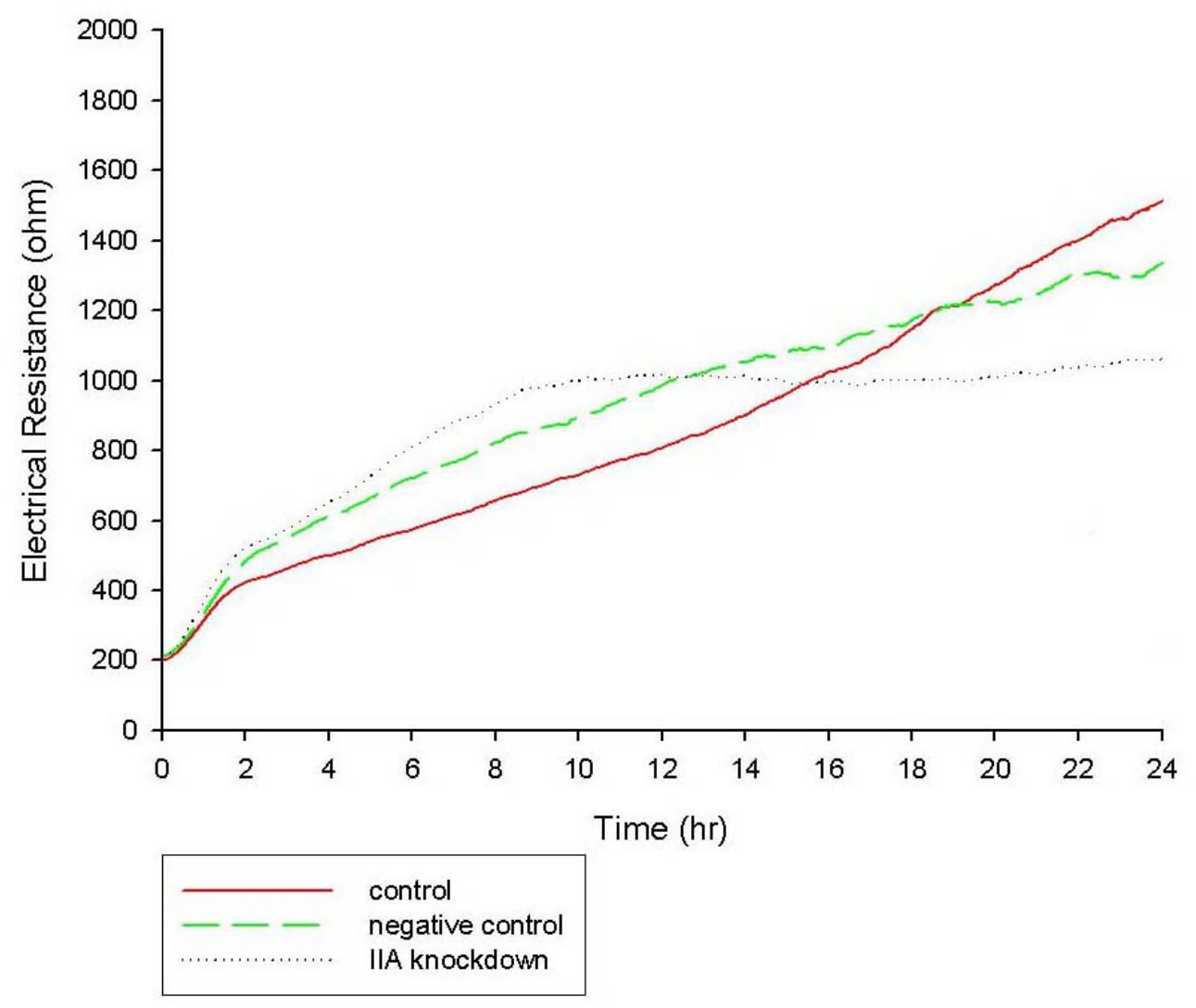

Figure 3.12: Endothelial cell attachment and spreading - Myosin IIA knockdown cells (black curve) initially had a larger slope than that of control curves. With time, the slope decreased, suggesting a lower cell adhesion function or cell division rate in infected cells than control cells. 


\section{RESULTS}

adhere and spread for 12 hours before motility measurements were performed. Cultures were washed with media containing $0.25 \%$ BSA 30 minutes prior to the start of an experiment to remove virus. Parallel cultures were maintained under identical conditions to assess the effects of the adenovirus constructs on the levels of myosin IIA. Western blot analysis showed that cells treated with adenovirus encoding shRNAi-IIA showed a $80 \%$ reduction of myosin IIA levels (Fig. 3.15). Figure 3.13 depicts a representative control motility movie showing the movement of endothelial cell every 30 minutes over a 5.5 hour time frame. After starting motility movie, pictures were captured every 60 seconds and the rate and path of cell migration were tracked at thirty minutes intervals for a total of 5.5 hours. The red dot placed on a cell at time zero allows one to follow the motility of an individual cell over the time frame outlined in specific protocols. Migration of control endothelial cell is depicted in Fig. 3.13 while the migratory path of myosin IIA knockdown cells is shown in Fig. 3.14. The rate of cell movement $(\mu \mathrm{m} / \mathrm{hr})$ is shown in Table 3.1. Myosin IIA knockdown cells (Fig. 3.14 were more spread and bigger than control cells (Fig. 3.13), which was consistent with the results we observed in static cultures. In addition, myosin IIA knockdown cells moved $35 \%$ faster $(13.54 \pm 5.34 \mu \mathrm{m} / \mathrm{hr})$ than control cells $(8.69 \pm 5.41 \mu \mathrm{m} / \mathrm{hr})$. These results suggested myosin IIA limited the rate of endothelial cell motility and loss of this molecule resulted in unfettered motion.

\begin{tabular}{|c|c|}
\hline & Average Velocity $(\mu \mathrm{m} / \mathrm{hr})$ \\
\hline Control & $8.69 \pm 5.41$ \\
IIA knockdown & $13.54 \pm 5.34$ \\
\hline
\end{tabular}

Table 3.1: Effect of loss of myosin IIA on endothelial cell motility - Result indicated that loss of myosin IIA increase cell motility.

To further analyze the cell motility, Fig. 3.16 illustrated the positions of cells at 30 minute interval for the duration of experiment. One axis is angular data (degree), another axis is radial data $(\mu \mathrm{m})$. The control endothelial cells tended to stay near the point of origin which indicated that most control cells barely moved during the 5.5 hour time lapse experiment. On the other hand, endothelial cells infected with ad-shRNAi-IIA displayed greater movement with variable directions and considerable distance. This phenomenon of increased cell migration suggested that loss of nonmuscle myosin IIA might increase endothelial cell motility. 

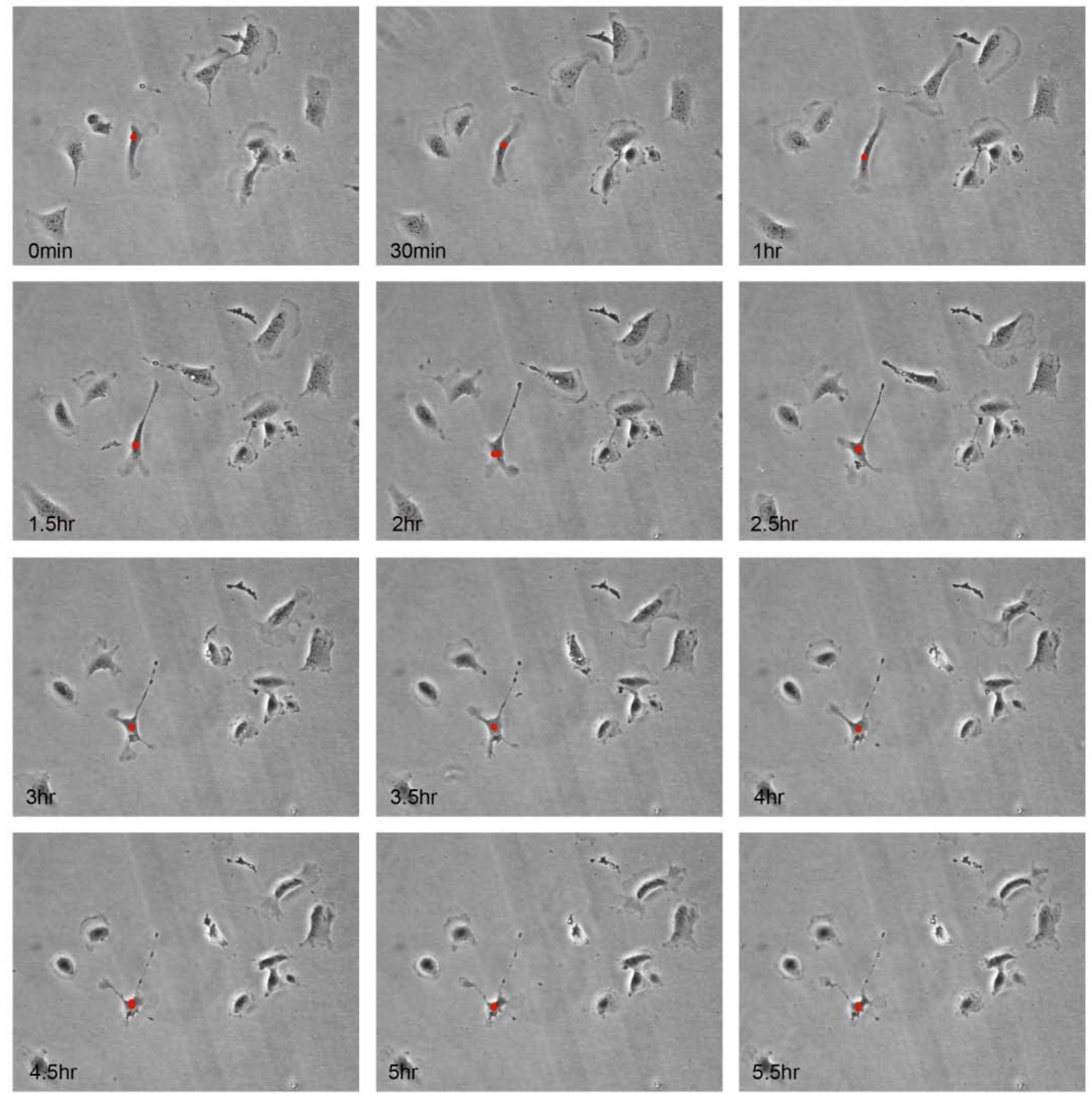

Figure 3.13: Motility of control cells - Pictures were taken every 30min for the first 5.5 hours. Red dot was added to help track one cell movement. No apparent net movement was observed as shown. 


\section{RESULTS}
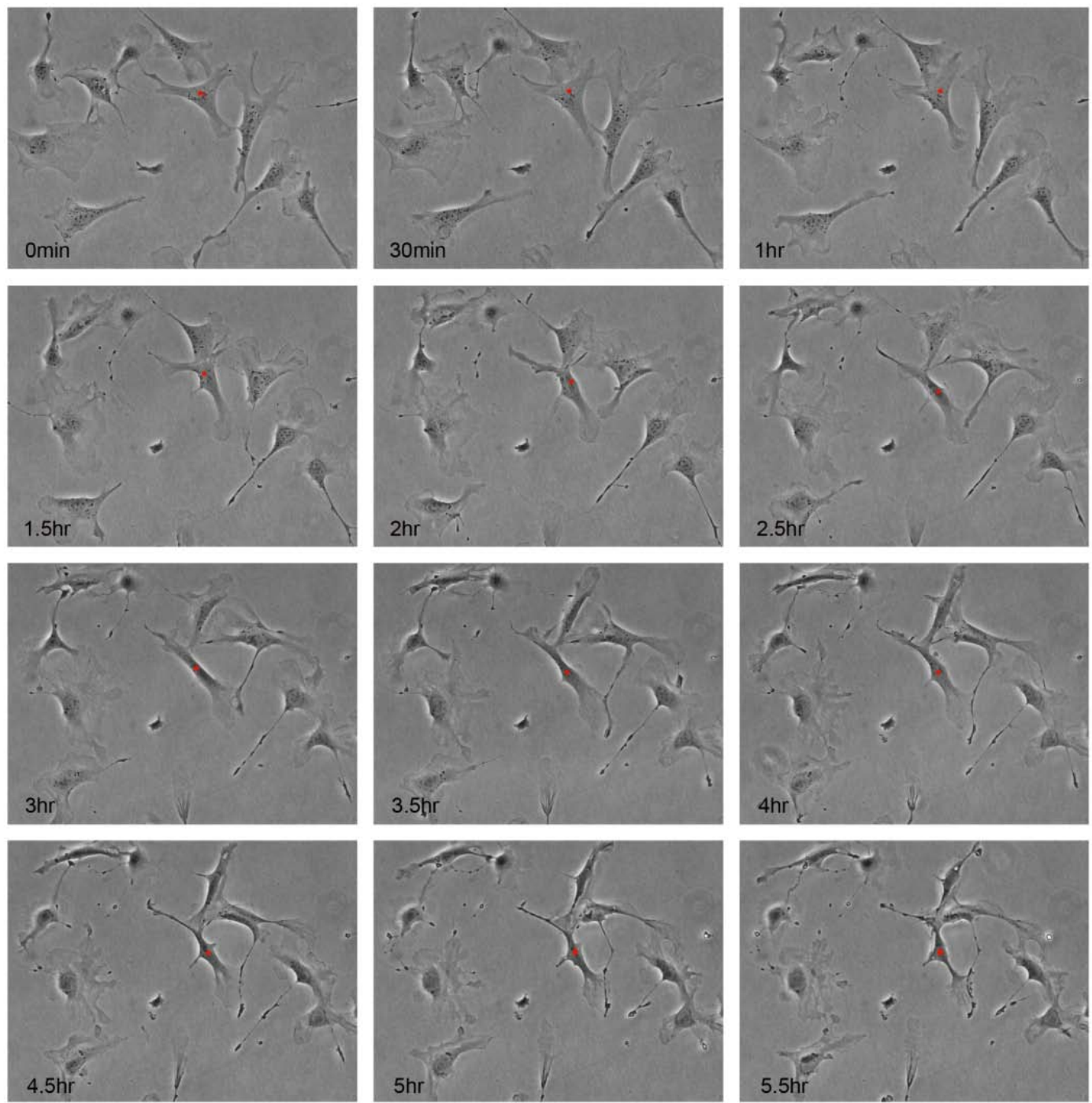

Figure 3.14: Motility of ad-shRNAi-IIA infected cells - Pictures were taken every $30 \mathrm{~min}$ for 5.5 hours. Red dot was added to help track one cell movement. It showed that cell shapes were changed apparently compared to control. 


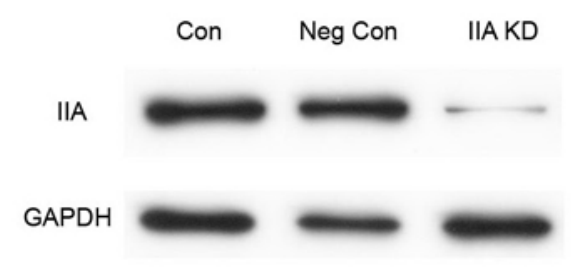

Figure 3.15: Effect of ad-shRNAi-IIA infection on myosin IIA content - Myosin II A level was clearly dereased in ad-shRNAi-IIA infected cells.

\subsection{Effects of Myosin IIA on Isometric Tension}

Since, actin and myosin are responsible for generating endothelial cell contractile forces [48], we sought to determine if loss of myosin IIA alters the contractile force produced by endothelial cells. In this last set of experiments, we directly measured the contractile force produced by endothelial cell depleted of myosin IIA. Isometric tension measurements were performed as outlined by Goeckeler and Wysolmerski [14]. Representative force tracings are shown in Fig. 3.17, Depletion of myosin IIA (green tracing) resulted in about $41 \%$ reduction in baseline tension compared to control (red tracing). Both myosin IIA knockdown and control monolayers rapidly increased their isometric tension upon stimulation with thrombin. However, myosin IIA depleted monolayers produced about $33 \%$ less force than control. Taken together, these results indicate that myosin IIA is essential for endothelial cells to generate basal tension and agonist-stimulated isometric tension. 


\section{Control}
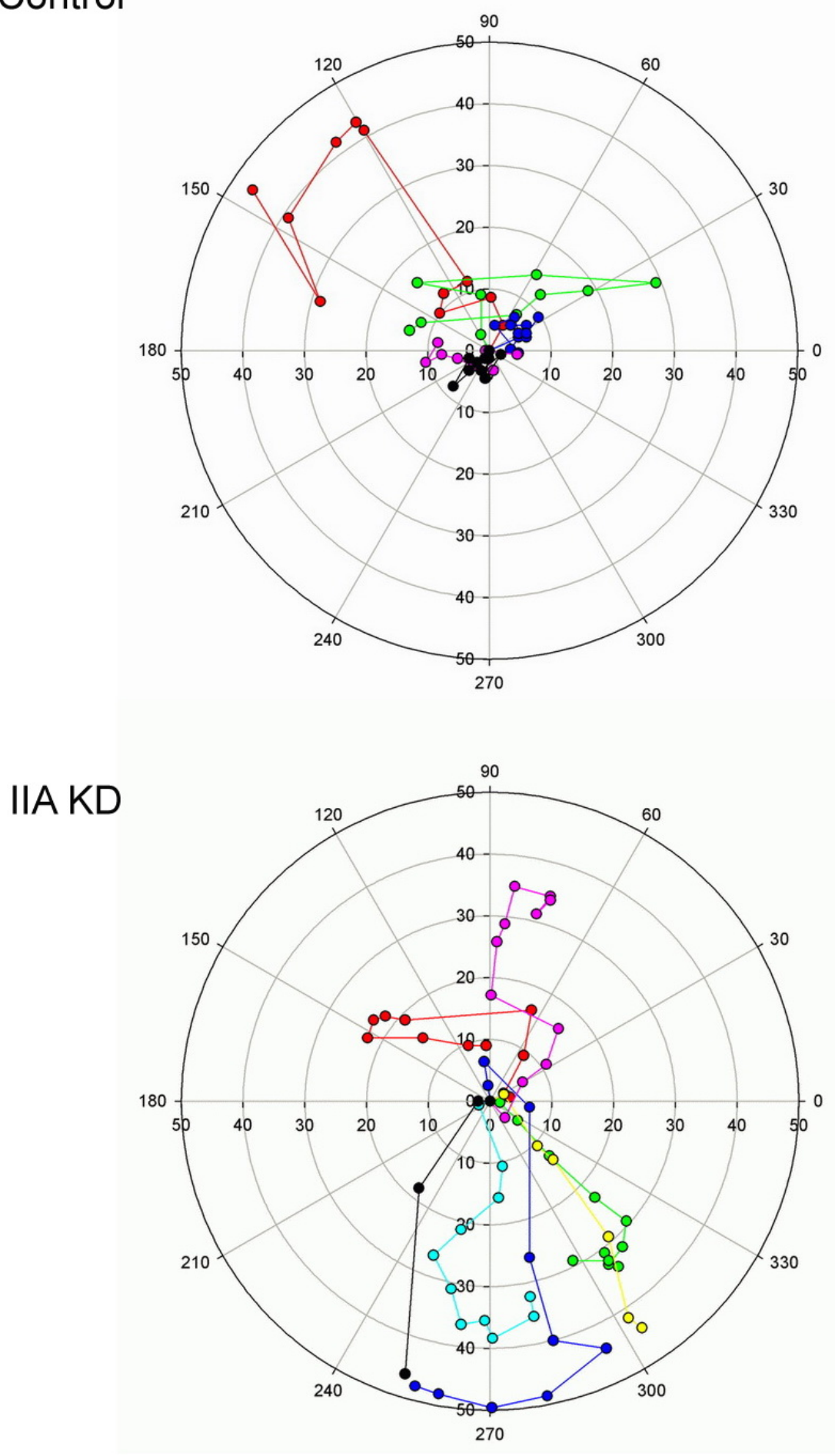

Figure 3.16: Path of cell movement - angular data (degree) vs radial data $(\mu \mathrm{m})$. 


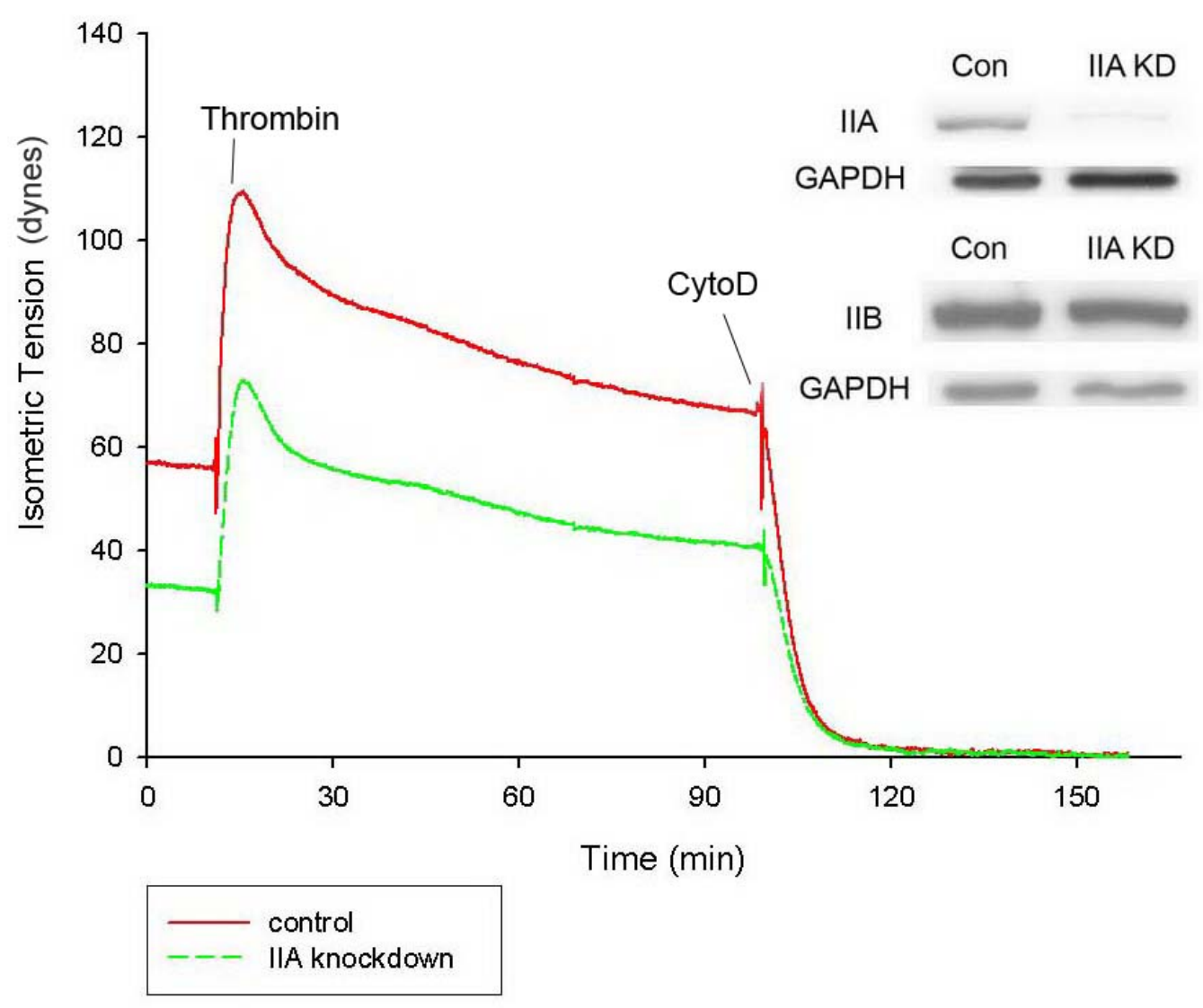

Figure 3.17: Force measurement of control and ad-shRNAi-IIA infected cells

- Red line presented control cells, the green line presented ad-shRNAi-IIA infected cells. After the baseline force was reached, the cells were stimulated with 2 unit $/ \mathrm{ml}$ thrombin, which induced a rapid increase in tension. After achieving peak tension, tension dropped to establish a new baseline force. Application of cytochalasin D (Cyto D) depolymerized actin filaments and abolished force production. Western blot result indicated the myosin levels in cells. 


\section{Chapter 4}

\section{Discussion}

This study analyzed the role of nonmuscle myosin IIA in regulating endothelial cell shape, motility and contraction by knocking down nonmuscle myosin IIA in endothelial cells with ad-shRNAi-IIA. The western blot result presented that about $90 \%$ percent of nonmuscle myosin IIA expression was decreased after MOI 100 per cell infection for 96 hours and it also showed that that nonmuscle myosin IIA expression could be effectively depleted without affecting the levels of the nonmuscle myosin IIB isoform.

Jeon et al. [49] provide evidence that nonmuscle myosin II is responsible for establishing cell polarity and retaining the cellular structure. The regulatory site of nonmuscle myosin regulatory light chain (MRLC) is directly phosphorylated by AMPkinase, which is an enzyme activated in response to energy deprivation. These investigators observed that the defect of AMP-kinase can lead to failure of activation of nonmuscle myosin II and dramatic abnormalities in cellular structure. However, after activation of AMP-kinase, they observed actin cytoskeleton polarization and dramatic changes in cell shape. Our morphology analyses were consistent with their observations that knocking down nonmuscle myosin IIA dramatically changed the cell shape and myoactin cytoskeleton. Our results provide further evidence that knocking down nonmuscle myosin IIA in endothelial cells causes decrease in number of F-actin bundles and increase of fine actin meshwork, which is also consistent with the observations of Sandquist et al [50].

Cell motility was analyzed in several experiments here, involving initial attachment and spreading measured by ECIS and random migration after attachment, measured by live cell imaging by Nikon swept field confocal system. In the ECIS result, myosin 
IIA knockdown cell presented a higher resistance during initial attachment, which indicated a faster attachment in myosin IIA knockeddown cells than control cells. This result is consistent with earlier conclusions Jay et al. 51. presented that myosin II contributes to cellular detachment and retraction, and Wylie and Chantler [52] deduced that nonmuscle myosin IIA drive neurite retraction in neuronal cells. Consistent with these conclusons, in the following random migration experiment by using Nikon swept field live cell confocal system, cells were observed more spread and larger in myosin IIA knockeddown cells and the moving rate of random migration was slightly higher than control cells.

Normally, contraction force helps detach the cell tail from the substratum. Since previous result demonstrated that the cellular detachment and retraction were inhibited in myosin IIA knockdown cells, we predicted that the contraction force will be decreased in myosin IIA knockeddown cells. In our laboratory, its observed that loss of nonmuscle myosin IIA not only cause morphology changes, it can also affect isometric tension production in endothelial cell. Our force measurement data showed that loss of myosin IIA can induce decrease in both baseline force and agonist-stimulated isometric tension produced in endothelial cells compared to control cells (Fig. 3.17). And the parallel western blot result also indicated that myosin IIA level was significantly decreased in ad-shRNAi-IIA infected cells while myosin IIB level was not affected by myosin IIA knockdown. These results suggested that the baseline force and agonist-stimulated isometric tension produced in myosin IIA knockdown cells may result primarily from nonmuscle myosin IIB. In the absence of myosin IIA, myosin IIB can still produce considerable baseline force and agonist-stimulated isometric tension force. We concluded that both myosin IIA and IIB contribute to the cell contractility of endothelial cell in normal condition. Loss of myosin IIA will result the decrease in the total baseline force produced as well as agonist-stimulated isometric tension force produced. In the absence of myosin IIA, can myosin IIB maintain contractile force to the same degree as in control cells or increase force production to partially compensate for the loss of the myosin IIA needs to be determined.

In our laboratory, we are also interested in the effect of loss of myosin IIB on endothelial cells. More surprising was our finding that in myosin IIB knockdown cells, actin filaments within the cytoplasm were not disrupted or lost like what we observed in myosin IIA knockdown cells previously stated. Myosin IIB deficient cells displayed 


\section{DISCUSSION}

regular cell shape and cytoskeleton, and actin filaments were bound into stress fibers running through cytoplasm. In addition, cells maintained their regular shapes, no exaggerated membrane protrusion occured. Taken together, loss of nonmuscle myosin IIA in endothelial cells leads to disruption of stress fibers resulting in apparent changes in cell shape and membrane protrusions. Meanwhile, different from those phenotypes in myosin IIA knockdown cells, in endothelial cells with ablation of nonmuscle myosin IIB while exclusively express nonmuscle myosin IIA isoform, cells displayed normal cell shape and actin filament. One hypothesis is that the stabilization of stress fiber as well as maintenance of cell shape depends heavily on nonmuscle myosin IIA, which is responsible for interacting with actin filaments and other cross-link proteins to form high order stress fibers in cells. In myosin IIA knockdown cells (Fig. 3.8), myosin IIB colocalized with short and disorganized stress fibers, suggesting that nonmuscle myosin IIB also contributes to stress fiber development, but might not be sufficient in maintenance the high order structure when nonmuscle myosin IIA is ablated from cells.

In summary, our data have shown that knocking down the expression of nonmuscle myosin IIA in mouse endothelial cells causes a dramatic decrease of stress fiber as well as alteration of actin cytoskeleton organization with concomitant changes in cell shape, migration and contractile force. Our data consistant with previous work by other investigators provided strong evidence supporting the idea that nonmuscle myosin IIA plays an important part in regulating cell shape, motility and contraction. More work is required for a further understanding of how these activities are monitored by the cell and the role myosin IIA interfere in endothelial cell monolayer permeability by regulating cytoskeleton. 


\section{References}

[1] G. Majno, S. M. Shea, and H. Leventhal, "Endothelial contraction induced by histaminetype mediators.," J Cell Biol., vol. 42, pp. 647-672, 1969. 1

[2] R. B. Wysolmerski and D. Lagunoff, "Ethchlorvynol-induced pulmonary edema in rats.," Am J Pathol, vol. 115, pp. 447-457, 1984. 1

[3] H. Lum and A. B. Malik, "Regulation of vascular endothelial barrier function.," Am. J. Physol, vol. 267, pp. L223-L241, 1994. 1]

[4] C. C. Michel and F. E. Curry, "Microvascular permeability.," Physiol Rev., vol. 79, pp. 70361, 1999. 1

[5] G. Majno and G. E. Palade, "Studies on inflammation: I. the effect of histamine and serotonin on vascular permeability: An electron microscopic study," J. Biophys. and Biochem. Cytol., vol. 11, pp. 571-605, 1961. 1

[6] P. J. D. Vecchio, A. Siflinger-Birnboim, P. N. Belloni, L. A. Holleran, H. Lum, and A. B. Malik, "Culture and characterization of pulmonary microvascular endothelial cells.," In Vitro Cell. Dev. Biol, vol. 28A, pp. 711-715, 1992. 1

[7] K. S. Galdal, S. A. Evensen, and E. Nilsen, "Thrombin-induced shape changes of cultured endothelial cells: metabolic and functional observations.," Thrombosis Res., vol. 32, pp. 5766, 1983. 1

[8] K. S. Galdal, S. A. Evensen, A.-S. Hoglund, and E. Nilsen, "Actin pools and actin microfilament organization in cultured human endothelial cells after exposure to thrombin.," British J of Haematology, vol. 58, pp. 617-625, 1984. 1

[9] D. Rotrosen and J. I. Gallin., "Histamine type i receptor occupancy increases endothelial cytosolic calcium, reduces f-actin, and promotes albumin diffusion across cultured endothelial monolayers," J Cell Biol., vol. 103, p. 23792387, 1986. 1

[10] D. M. Shasby, S. S. Shasby, J. M. Sullivan, and M. J. Peach, "Role of endothelial cell cytoskeleton in control of endothelial permeability," Circ Res., vol. 51, pp. 657-661, 1982. 1 


\section{REFERENCES}

[11] R. B. Wysolmerski and D. Lagunoff, "The effect of ethchlorvynol on cultured endothelial cells. a model for the study of the mechanism of increased vascular permeability.," $A m J$ Pathol, vol. 119, pp. 505-512, 1985. 1.2

[12] R. B. Wysolmerski and D. Lagunoff, "Involvement of myosin light-chain kinase in endothelial cell retraction.," Proc. Natl. Acad. Sci. USA, vol. 87, pp. 16-20, 1990. 2

[13] M. S. Kolodney and R. B. Wysolmerski, "Isometric contraction by fibroblasts and endothelial cells in tissue culture: A quantitative study.," J Cell Biol, vol. 117, pp. 73-82, 1992. 2

[14] Z. M. Goeckeler and R. B. Wysolmerski, "Myosin light chain kinase-regulated endothelial cell contraction: the relationship between isometric tension, actin polymerization, and myosin phosphorylation," J Cell Biol., vol. 130, pp. 613-627, 1995. 2, 32

[15] R. B. Wysolmerski and D. Lagunoff, "Inhibition of endothelial cell retraction by atp depletion.," Am J Pathol, vol. 132, pp. 28-37, 1988. 2

[16] K. Kitazumi and K. Tasaka, "Thrombin-stimulated phosphorylation of myosin light chain and its possible involvement in endothelin-1 secretion from porcine aortic endothelial cells.," Biochem. Pharmacology, vol. 43, pp. 1707-1709, 1992. 2

[17] R. B. Wysolmerski and D. Lagunoff, "Regulation of permeabilized endothelial cell retraction by myosin phosphorylation.," Am J Pathol, vol. 261, pp. C32-C40, 1991. 2

[18] M. Ikebe, D. J. Hartshorne, and M. Elzinga, "Identification, phosphorylation and dephosphorylation of a second site for myosin light chain kinase on the 20,000-dalton light chain of smooth muscle myosin.," J Biol. Chem., vol. 261, pp. 36-39, 1986. 2 3

[19] S. Kawamoto and R. S. Adelstein, "Characterization of myosin heavy chains in cultured aorta smooth muscle cells.," J Biol. Chem., vol. 262, pp. 7282-7288, 1987. 2

[20] J. D. Strauss, P. D. Lanerolle, and R. J. Paul, "Effects of myosin kinase inhibiting peptide on contractility and lc20 phosphorylation in skinned smooth muscle.," Am J Pathol, vol. 262, pp. C1437-C1445, 1992. 2

[21] J. T. Stull, M. G. Tansey, D. C. Tang, R. A. Word, and K. E. Kamm, "Phosphorylation of myosin light chain kinase: a cellular mechanism for ca2+ desensitization.," Mol Cell Biochem, vol. 127/128, pp. 229-237, 1993. 2

[22] G. Holzapfel, J. Wehland, and K. Weber, "Calcium control of actin-myosin based contraction in triton models of mouse $3 \mathrm{t} 3$ fibroblasts is mediated by the myosin light chain kinase (mlck)-calmodulin complex.," Exp. Cell Res., vol. 148, pp. 117-126, 1983. 2

[23] W. Z. Cande and R. M. Ezzell, "Evidence for regulation of lamellipodial and tail contraction of glycerinated chicken embryonic fibroblasts by myosin light chain kinase.," Cell Motil Cytoskeleton, vol. 6, pp. 640-648, 1986. 2 
[24] K. A. Giuliano, J. Kolega, R. L. DeBiasio, and D. L. Taylor, "Myosin ii phosphorylation and the dynamics of stress fibers in serum-deprived and stimulated fibroblasts.," Mol Biol Cell, vol. 3, pp. 1037-1048, 1992. 2

[25] R. I. Ludowyke, I. Peleg, M. A. Beaven, and R. S. Adelstein, "Antigen-induced secretion of histamine and the phosphorylation of myosin by protein kinase $\mathrm{c}$ in rat basophilic leukemia cells.," J Biol Chem., vol. 264, pp. 12492-12501, 1989. 2

[26] O. H. Choi, R. S. Adelstein, and M. A. Beaven, "Secretion from rat basophilic rbl-2h3 cells is associated with diphosphorylation of myosin light chains by myosin light chain kinase as well as phosphorylation by protein kinase c.," J Biol Chem., vol. 269, pp. 536-541, 1994. 2

[27] E. A. Hixenbaugh, Z. M. Goeckeler, N. N. P. R. B. W. S. C. Silverstein, and A. J. Huang, "Stimulated neutrophils induce myosin light chain phosphorylation and isometric tension in endothelial cells.," Am J Physiol., vol. 273(2 Pt 2), pp. H981-988, 1997. 2

[28] H. L. Sweeney, Z. Yang, G. Zhi, J. T. Stull, and K. M. Trybus, "Charge replacement near the phosphorylatable serine of the myosin regulatory light chain mimics aspects of phosphorylation.," Proc Natl Acad Sci U S A., vol. 91, pp. 1490-1494, 1994. 2

[29] J. G. Garcia, H. W. Davis, and C. E. Patterson, "Regulation of endothelial cell gap formation and barrier dysfunction: role of myosin light chain phosphorylation.," J Cell Physiol., vol. 163, pp. 510-522, 1995. 2

[30] A. B. Moy, S. S. Shasby, and B. D. S. D. M. Shasby, "The effect of histamine and cyclic adenosine monophosphate on myosin light chain phosphorylation in human umbilical vein endothelial cells.," J Clin Invest., vol. 92, pp. 1198-1206, 1993. 2

[31] D. K. Blumenthal and J. T. Stull, "Activation of skeletal muscle myosin light chain kinase by calcium $(2+)$ and calmodulin.," Biochemistry, vol. 19, pp. 5608-14, 1980. 2

[32] R. Craig, R. Smith, and J. Kendrick-Jones, "Light-chain phosphorylation controls the conformation of vertebrate non-muscle and smooth muscle myosin molecules.," Nature, vol. 302, pp. 436-439, 1983. 2, 3

[33] M. Ikebe, J. Koretz, and D. J. Hartshorne, "Effects of phosphorylation of light chain residues threonine 18 and serine 19 on the properties and conformation of smooth muscle myosin.," J Biol Chem., vol. 263, pp. 6432-6437, 1988. 2,3

[34] J. L. Tan, S. Ravid, and J. A. Spudich, "Control of nonmuscle myosins by phosphorylation.," Annu Rev Biochem., vol. 61, pp. 721-759, 1992. 3

[35] D. C. Tang, J. T. Stull, Y. Kubota, and K. E. Kamm, "Regulation of the ca2+ dependence of smooth muscle contraction.," J Biol Chem., vol. 267, pp. 11839-11845, 1992. 3

[36] J. E. Fox and D. R. Phillips, "Role of phosphorylation in mediating the association of myosin with the cytoskeletal structures of human platelets.," J Biol Chem., vol. 257, pp. 4120-6., 1982. 3 


\section{REFERENCES}

[37] J. L. Daniel and J. R. Sellers, "Purification and characterization of platelet myosin.," Methods Enzymol., vol. 215, pp. 78-88, 1992. 3

[38] C. A. Kelley, J. R. Sellers, P. K. Goldsmith, and R. S. Adelstein, "Smooth muscle myosin is composed of homodimeric heavy chains.," J Biol Chem., vol. 267, pp. 2127-2130., 1992. 3

[39] C. A. Kelley, J. R. Sellers, D. L. Gard, D. Bui, R. S. Adelstein, and I. C. Baines, "Xenopus nonmuscle myosin heavy chain isoforms have different subcellular localizations and enzymatic activities.," J Cell Biol., vol. 134, pp. 675-87, 1996. 3

[40] M. Vicente-Manzanares, X. Ma, R. S. Adelstein, and A. R. Horwitz, "Non-muscle myosin ii takes centre stage in cell adhesion and migration," Nat Rev Mol Cell Biol., vol. 10, pp. 778-790, 2009. 3

[41] Y. Cai, N. Biais, G. Giannone, M. Tanase, G. Jiang, J. M. Hofman, C. H. Wiggins, P. Silberzan, A. Buguin, B. Ladoux, and M. P. Sheetz, "Nonmuscle myosin iia-dependent force inhibits cell spreading and drives f-actin flow," Biophys J., vol. 91, pp. 3907-3920, 2006. 3

[42] M. A. Conti and R. S. Adelstein, "Nonmuscle myosin ii moves in new directions," J Cell Sci., vol. 121, pp. 11-18, 2008. 3

[43] S. M. Dudek, J. R. Jacobson, E. T. Chiang, K. G. Birukov, P. Wang, X. Zhan, and J. G. Garcia, "Pulmonary endothelial cell barrier enhancement by sphingosine 1-phosphate: roles for cortactin and myosin light chain kinase," J Biol Chem., vol. 279, pp. 24692-24700, 2004. 3

[44] N. S. Umapathya, Z. Fana, E. A. Zemskova, I. B. Alievaa, S. M. Blacka, and A. D. Verin, "Molecular mechanisms involved in adenosine-induced endothelial cell barrier enhancement," Vascular Pharmacology, p. doi:10.1016/j.vph.2009.12.008, 2010. 3

[45] R. Dickinson and R. Tranquillo, "Optimal estimation of cell movement indices from the statistical analysis of cell tracking data," AIChE J, vol. 39, pp. 1995-2010, 1993.

[46] Y. Tseng, T. P. Kole, and D. Wirtz, "Micromechanical mapping of live cells by multipleparticle-tracking microrheology," Biophys J, vol. 83, pp. 3162-3176, 2002.

[47] T. P. Kole, Y. Tseng, and D. Wirtz, "Intracellular microrheology as a tool for the measurement of the local mechanical properties of live cells," Methods Cell Biol, vol. 78, pp. 45-64, 2004.

[48] O. M. Rossier, N. Gauthier, N. Biais, W. Vonnegut, M. A. Fardin, P. Avigan, E. R. Heller, A. Mathur, S. Ghassemi, M. S. Koeckert, J. C. Hone, and M. P. Sheetz, "Force generated by actomyosin contraction builds bridges between adhesive contacts," EMBO, vol. 29, pp. $1055-1068,2010$. 27 
[49] T. J. Jeon, D.-J. Lee, S. Merlot, G. Weeks, and R. A. Firtel, "Rap1 controls cell adhesion and cell motility through the regulation of myosin ii," J Cell Biol., vol. 176, p. 10211033, 2007. 30

[50] J. C. Sandquist, K. I. Swenson, K. A. Demali, K. Burridge, and A. R. Means, "Rho kinase differentially regulates phosphorylation of nonmuscle myosin ii isoforms a and b during cell rounding and migration," J Biol Chem., vol. 281, pp. 35873-35883, 2006. 30

[51] P. Y. Jay, P. A. Pham, S. A. Wong, and E. L. Elson, "A mechanical function of myosin ii in cell motility," J Cell Sci., vol. 108, pp. 387-393, 1995. 31

[52] S. R. Wylie and P. D. Chantler, "Myosin iia drives neurite retraction," Mol Biol Cell., vol. 14 , pp. $4654-4666,2003$. 31 